\title{
A Review of Heterolytic Synthesis Methodologies for Organotri- and Organotetrasulfane Synthesis
}

\author{
Doaa Alia,b \\ Yasien Amer ${ }^{\text {(D) }}$ \\ Wade F. Petersen ${ }^{a}$ (D) \\ Catherine H. Kaschulab (D) \\ Roger Hunter*a (iD) \\ a Department of Chemistry, University of Cape Town, \\ Rondebosch, 7701, South Africa \\ Roger.Hunter@uct.ac.za \\ b Department of Chemistry and Polymer Science, \\ Stellenbosch University, Stellenbosch 7600, South Africa
}

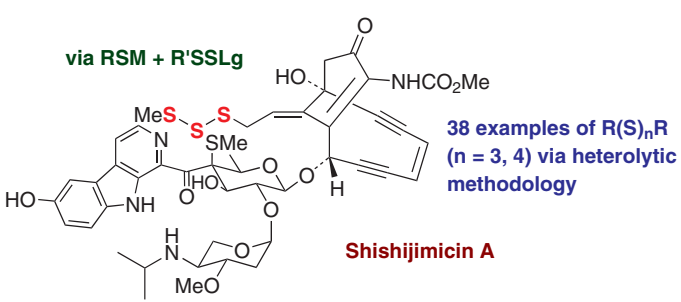

fer to double bonds is covered in previous reports, ${ }^{1}$ which will not be covered here. The same applies to the reduction of organotri- and organotetrasulfane oxides $\left(\mathrm{S}=\mathrm{O}\right.$ and $\left.\mathrm{SO}_{2}\right)$ as well as the extrusion of sulfur from a polysulfane using a phosphine.

The mechanistic and historical-account format of this review distinguishes it from other similar reports; there is also emphasis on updating new developments in the last twenty years or so since the last reviews. ${ }^{1}$ We have adopted usage of the term sulfane in line with IUPAC nomenclature rather than the popular and much used (particularly in the older literature) 'sulfide', retaining the word 'sulfide' for inorganic salts of sulfur only. The descriptions symmetri$\mathrm{cal} /$ unsymmetrical sulfane (tri- or tetra) and homo/heterosulfane will be used interchangeably. In the main text, organotrisulfane and organotetrasulfane will be abbreviated to trisulfane and tetrasulfane, respectively.

\section{Mechanistic Considerations for Synthesis}

In the present era of retrosynthesis, it is useful to start this review by rationally identifying the various heterolytic disconnection points on offer to the synthetic chemist for tri- and tetrasulfane synthesis as shown in Figure 2. Using symmetrical (homo) targets $\mathrm{R}(\mathrm{S})_{n} \mathrm{R}$ for analysis, with $n=3$ (trisulfane) and 4 (tetrasulfane), Figure 2 identifies two and three disconnection points, (i)-(v), for an organotri- and organotetrasulfane, respectively. These translate into a variety of heterolytic nucleophilic and electrophilic sulfur synthons in each case.

An examination of known literature methodologies for accessing the two chemotypes reveals that only two types of overall disconnection have representation. These involve the coupling of either two synthons, which arises from a one-bond disconnection, involving any of the (i)-(v) discon- 


Biographical Sketches
$\begin{array}{lll}\text { Doaa Ali studied chemistry at the } & \text { lenbosch). Her PhD project has } & \text { studying the mechanism of cyto- } \\ \text { University of Khartoum, Sudan, } & \text { concerned developing new } & \text { toxicity of trisulfanes from garlic } \\ \text { graduating with an MSc in 2012. } & \text { synthetic methodologies for ac- } & \text { against cancer cells. In recognition } \\ \text { In 2016, she came to the Universi- } & \text { cessing unsymmetrical organo- } & \text { of her work, she recently received } \\ \text { ty of Cape Town on an OWSD } & \text { trisulfanes via low-temperature a L'Oréal-UNESCO, Women in Sci- } \\ \text { disulfanyl anion transfer to an or- } & \text { ence Award in the 'Young Talents } \\ \text { Ph.D. Fellowship to study under } & \text { in Sub-Saharan' category. }\end{array}$
Catherine Kaschula (now at Stel-

Yasien Amer was born in Cape Town, South Africa, but grew up in Egypt, later returning to Cape Town to complete his secondary education. In 2018, he obtained his BSc degree in chemistry from

Wade Frank Petersen was born in Cape Town, South Africa and studied chemistry at the University of Cape Town, where he graduated with a BSC Hons in 2009 and a Ph.D. in Organic Chemistry in 2015. His Ph.D. supervisor was Professor Roger Hunter, working in the area of asymmetric synthesis. After two years postdoctoral studies with Professor Richard

Catherine Hart Kaschula studied chemistry at the University of the Witwatersrand, Johannesburg, South Africa and then received her Ph.D. from the University of Cape Town in 2002 in the field of synthetic and medicinal chemistry on structure-activity relationships of the antimalarial drug chloroquine. Her Ph.D. supervisors were Professors Timothy Egan and Roger Hunter in the Chemistry Depart-

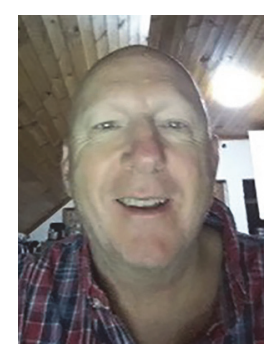

Roger Hunter studied for both his BSc Hons and Ph.D. in chemistry at Imperial College, London in the 1970s, graduating in 1975 and 1978, respectively. His Ph.D. supervisors were the Nobel Laureate, Professor Sir Derek Barton, and Dr Graham Mellows. Following a Royal Society European Science Exchange Fellowship doing postdoctoral research with Professor Juan-Julio Bonet at the Instituto Químico de Sarrià (IQS) in Barcelona, Spain (1978-1980), he returned to London in 1980 to take up a second postdoctoral fellowship, with Professor Peter the University of Cape Town followed by an Honors degree in 2019. He is currently pursuing his MSc with Professor Roger Hunter on the development of a new synthetic method for preparing un-

Taylor at the University of York, UK, working in the field of radical chemistry and $\mathrm{C}-\mathrm{H}$ activation, he returned to the University of Cape Town to start his independent academic career as a Lecturer in $\mathrm{Or}$ ganic Chemistry in 2018. In 2019, he was awarded a UK Royal Society/African Academy of Sciences Future Leaders African Independent Research (FLAIR) Fellowship.

ment. Following a postdoctoral stint at the Jules Stein Eye Institute, UCLA School of Medicine in California with Professor Gabriel Travis, she returned to Cape Town in 2006 to take up a second postdoctoral position with Professor Iqbal Parker in the Department of Medical Biochemistry at the UCT Medical School. In 2013, she took up a position of Lecturer in the Chemistry Department at UCT,

Garratt at University College, London. In 1983, he left the UK once again, taking up a Lectureship in Organic Chemistry at the University of the Witwatersrand, Johannesburg, South Africa. Following a move to the University of Cape Town (UCT) in 1989 as an Associate Professor, he eventually took up the Mally Chair as head of Organic Chemistry in 2004. He now holds an Emeritus Professorship at UCT as a UCT Senior Research Scholar. Over the years, he has held sabbatical leave periods with Sir Fraser Stoddart at Birmingham in 1991, Professor Philip Bulman symmetrical organotetrasulfanes. Such derivatives are relevant to studying chemical biology aspects of the cytotoxicity of OSCs from garlic against cancer cells.

His research interests are focused towards developing enantioselective methods for the construction of biologically important molecules relevant to medicinal chemistry and chemical biology, specifically through the use of photocatalysis and formal $\mathrm{C}-\mathrm{H}$ activation strategies.

moving to the Department of Chemistry and Polymer Science at Stellenbosch University in 2017 as Senior Lecturer. Her research centres on using an interdisciplinary approach to solving chemical biology questions in cancer prevention and treatment, specifically in the use of natural product small molecules such as the garlic polysulfanes.

Page at Loughborough in 1999 and Professor Karen Anderson on a Fulbright scholarship at Yale University in 2007. His research interests broadly focus around developing novel organic synthesis methodology to address aspects of natural product total synthesis, medicinal chemistry and chemical biology. In the last decade or so, he has applied his interest in organosulfur methodology towards chemical biology studies of organosulfur compounds (OSCs) from garlic in the context of their cancer-cell cytotoxicity. 


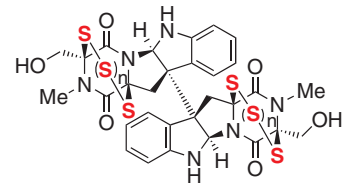<smiles>COc1cc(CCN)c2c(c1OC)SSSSS2</smiles>

$\mathrm{n}=1 ;$ (+)-Chaetosin C

$n=2 ;(+)-12,12 '-D i d e o x y c h e t r a c i n ~ A$

ref 3

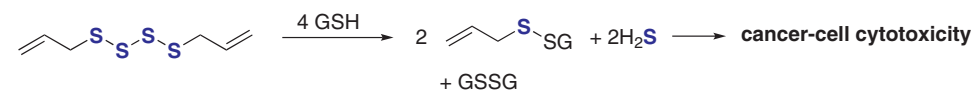

ref 4

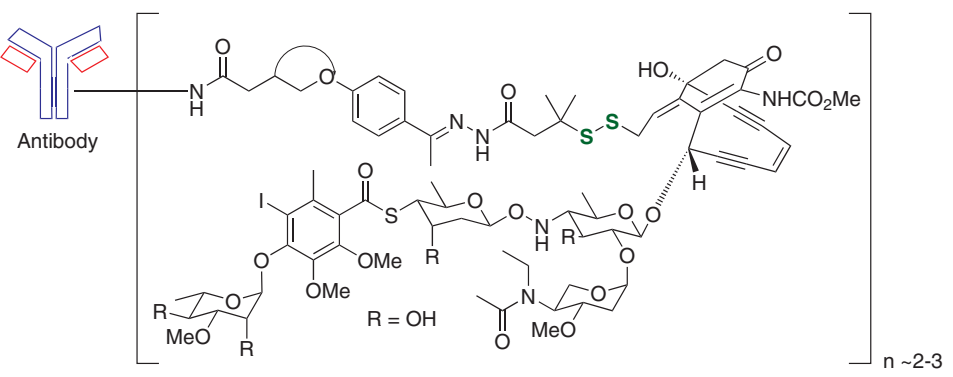

Gemtuzumab Ozogamicin (Mylotarg) - ADC for CD33-positive acute myeloid leukaemia

ref 5

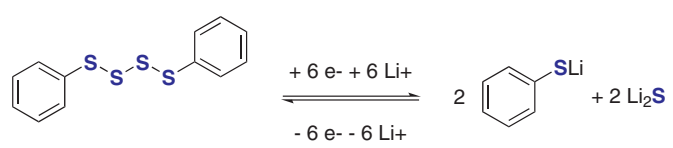

Figure 1 Some examples of polysulfanes from modern literature

nections in Figure 2. Alternatively, one observes three synthons from a two-bond disconnection sequence. Each type assumes that a one-pot reaction can access the respective target. One-bond disconnections can access unsymmetrical tri- and tetrasulfanes, while two-bond disconnections are realistically only suitable for homosulfane synthesis (see Figure 2 for examples).

The various methodological approaches known are illustrated in Table 1, in which the nucleophilic partner is always placed first in the combination description, and the numbers in parentheses refer to the number of sulfurs in any synthon.

\subsection{Methodology $\mathrm{A}: \mathrm{M}(\mathrm{S})_{n} \mathrm{M}(n=3,4)+2 \times \mathrm{RX}$}

The earliest report of a dialkylation of trisulfide dianion was more than a hundred years ago $^{7}$ when Strecker (that is Willem, not Adolph, the latter famous for the Strecker reaction) demonstrated that dimethyl trisulfane could be prepared by reaction of $\mathrm{Na}_{2} \mathrm{~S}_{3}$ (prepared from $\mathrm{Na}_{2} \mathrm{~S}+2 \mathrm{~S}$ ) with dimethyl sulfate in about $80 \%$ isolated yield. The trisulfane was purified by vacuum distillation ( $\mathrm{bp}_{14 \mathrm{~mm}}, 60-62{ }^{\circ} \mathrm{C}$ ) out of the mixture of polysulfane products. The trisulfane could also be prepared from $\mathrm{Na}_{2} \mathrm{~S}_{5}$ and dimethyl sulfate followed by heating the product to convert the pentasulfane into its trisulfane. A few years later, in 1923, Richard William Riding and John Smeath Thomas, working at the Universities of Cape Town and Liverpool, respectively, reported that

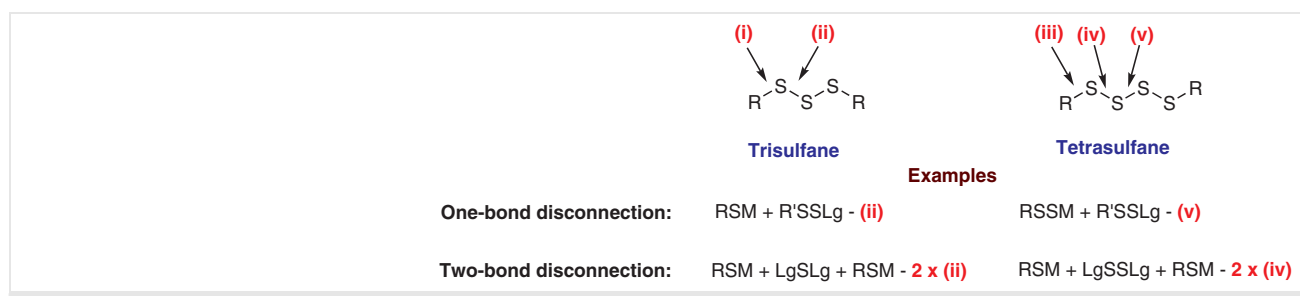

Figure 2 Disconnection points and examples for organotri- and organotetrasulfanes 
Table 1 Known Heterolytic Disconnections for Organotri- and Organotetrasulfane Synthesis ( $M$ = Metal, H; $L g$ = Leaving group)

\begin{tabular}{|c|c|c|c|c|}
\hline Type & Number of disconnections & Combination & Description & Product \\
\hline A & Two & $\begin{array}{l}{[3+0+0]} \\
{[4+0+0]}\end{array}$ & $\begin{array}{l}M S_{3} M+R X+R X \\
M S_{4} M+R X+R X\end{array}$ & $\begin{array}{l}\text { trisulfane } \\
\text { tetrasulfane }\end{array}$ \\
\hline B & Two & $\begin{array}{l}{[1+1+1]} \\
{[2+1+1]}\end{array}$ & $\begin{array}{l}M S M+R S L g+R S L g \\
M_{2} M+R S L g+R S L g\end{array}$ & $\begin{array}{l}\text { trisulfane } \\
\text { tetrasulfane }\end{array}$ \\
\hline C & Two & $\begin{array}{l}{[1+1+1]} \\
{[1+1+2]}\end{array}$ & $\begin{array}{l}R S M+R S M+L g S L g \\
R S M+R S M+L^{2} S_{2} L g\end{array}$ & $\begin{array}{l}\text { trisulfane } \\
\text { tetrasulfane }\end{array}$ \\
\hline D & One & $\begin{array}{l}{[2+1]} \\
{[2+2]} \\
{[3+1]}\end{array}$ & $\begin{array}{l}\text { RSSM + RSLg } \\
\text { RSSM + RSSLg } \\
\text { RSSSM + RSLg }\end{array}$ & $\begin{array}{l}\text { trisulfane } \\
\text { tetrasulfane } \\
\text { tetrasulfane }\end{array}$ \\
\hline $\mathrm{E}$ & One & $\begin{array}{l}{[1+2]} \\
{[1+3]} \\
{[0+3]}\end{array}$ & $\begin{array}{l}\text { RSM + RSSLg } \\
\text { RSM + RSSSLg } \\
\text { RM + RSSSLg }\end{array}$ & $\begin{array}{l}\text { trisulfane } \\
\text { tetrasulfane } \\
\text { trisulfane }\end{array}$ \\
\hline
\end{tabular}

$\mathrm{K}_{2} \mathrm{~S}_{5}$ reacted with alkyl iodides to give pentasulfanes. ${ }^{8}$ On heating, these also rearranged to the disulfane and sulfur, which then combined to give the trisulfane mixed in with the disulfane. These two reports set the scene for this methodology for the next hundred years, highlighting its limitations due to the interconversion of polysulfide anions, a relevant chemistry aspect that is eminently supported by the inorganic literature. ${ }^{9}$ Hence, one can start with the stable $\mathrm{Na}_{2} \mathrm{~S}$ and add appropriate equivalents of sulfur to convert into the tri $\left(\mathrm{Na}_{2} \mathrm{~S}_{3}\right)^{10 \mathrm{a}}$ or tetrasulfide $\left(\mathrm{Na}_{2} \mathrm{~S}_{4}\right)$ dianions, ${ }^{10 \mathrm{~b}}$ but these will always exist in an equilibrium of polysulfide anions. No-one has found a solution to this problem as yet, and hence the best that one can conclude for this methodological option is that although straightforward to carry out, it is limited regarding only being able to access mixtures of homopolysulfanes (these are difficult to separate even using C18 reverse-phase chromatography when $R$ is non-polar), in which the organic $\mathrm{R}$ groups are mainly limited to $S_{N} 2$-active groups in the halide $\mathrm{RX}\left(\mathrm{S}_{\mathrm{N}} \mathrm{Ar}\right.$ reaction on a chloro, nitroaromatic has been demonstrated). ${ }^{11}$ Needless to say, this is not the method of choice for producing tetrasulfanes in pure form, and definitely not unsymmetrical versions. The three reviews ${ }^{1}$ cited in the introduction cover many examples of this approach cited during the twentieth century, but all of them suffer from these limitations. Rather than start with the inorganic sulfide, substituting with sulfur and an inorganic hydroxide together with an alkyl halide is also known ${ }^{12 a-c}$ in which it is safe to assume that the reaction proceeds via a polysulfide anion or dianion and hence suffers from the same limitations (hydrazine as a reductant may also be added to reduce $\mathrm{S}_{8}$ to produce reactive polysulfide anions). ${ }^{12 \mathrm{~b}}$ Similarly, one may start from sulfur with either sodium metal in an aprotic solvent like DME (Scheme 1, entry 1$),{ }^{13}$ or a tin/copper promotor (Scheme 1 , entry 2), ${ }^{14}$ but, once again, reaction in each case with RX yields a range of polysulfanes. Interestingly, reaction of sulfur with acrylonitrile in DMF and ammonia yields a moderate yield (49\%) of the trisulfane, which is claimed by the au- thors to proceed via conjugate addition of a sulfur radical anion (Scheme 1, entry 3). ${ }^{15}$ Nucleophilic substitution of alkyl halides by electrochemically generated polysulfide anions in DMA is also known. ${ }^{16}$ Cyclic tri- and tetrasulfanes are also known to be available using methodology $\mathbf{A}$, and have been fully reviewed, ${ }^{1}$ but once again, mixtures of polysulfanes are invariably produced as with the acyclic variants (Scheme 1, entries 4 and 5). ${ }^{17,18}$ Scheme 1 illustrates entries 1-5 based on examples from the last twenty years or so.

\subsection{Methodology B: $M(S)_{n} M(n=1,2)+2 \times$ RSLg}

Seminal work by Brian Milligan and John Swan in the early 1960 s $^{19,20}$ established the first examples of trisulfane synthesis using methodology $\mathbf{B}$, in which a Bunte salt (an $S$ alkyl or $S$-arylthiosulfate salt as $\mathrm{RSSO}_{3}{ }^{-} \mathrm{M}^{+}$) was used as the sulfenylating agent of sodium sulfide $\left(\mathrm{Na}_{2} \mathrm{~S}\right)$, which is the most reliable of all the sulfide salts in regards to purity and constitution. In cases involving a reactive RSLg, $\mathrm{H}_{2} \mathrm{~S}$ can be used as the monosulfur nucleophilic source, and once again, earlier reviews on polysulfanes ${ }^{1}$ give an extensive coverage of this approach. Bunte salts first appeared in the literature in 1874 when Hans Bunte reacted thiosulfate with ethyl bromide, ${ }^{21}$ and Xuefeng Jiang has recently reviewed their usage in sulfur-carbon bond formation. ${ }^{22}$ Milligan and Swan noted that the primary products of the first substitution, namely sulphite ion $\left(\mathrm{SO}_{3}{ }^{2-}\right)$ and disulfanyl anion (RSS-), could undergo subsequent reactions with the trisulfane once formed to generate di- and tetrasulfanes as by-products, respectively. This they found could be suppressed using formaldehyde, and the reaction was optimised recently by Hemant Srivastava and Krishna Bhabak in 2019 (entry 6, Scheme 2). ${ }^{23}$ Milligan and Swan also went on to use their method to prepare cyclic trisulfanes from diBunte salts (Scheme 2, entry 7). ${ }^{24}$ Indeed, cyclic polysul- 


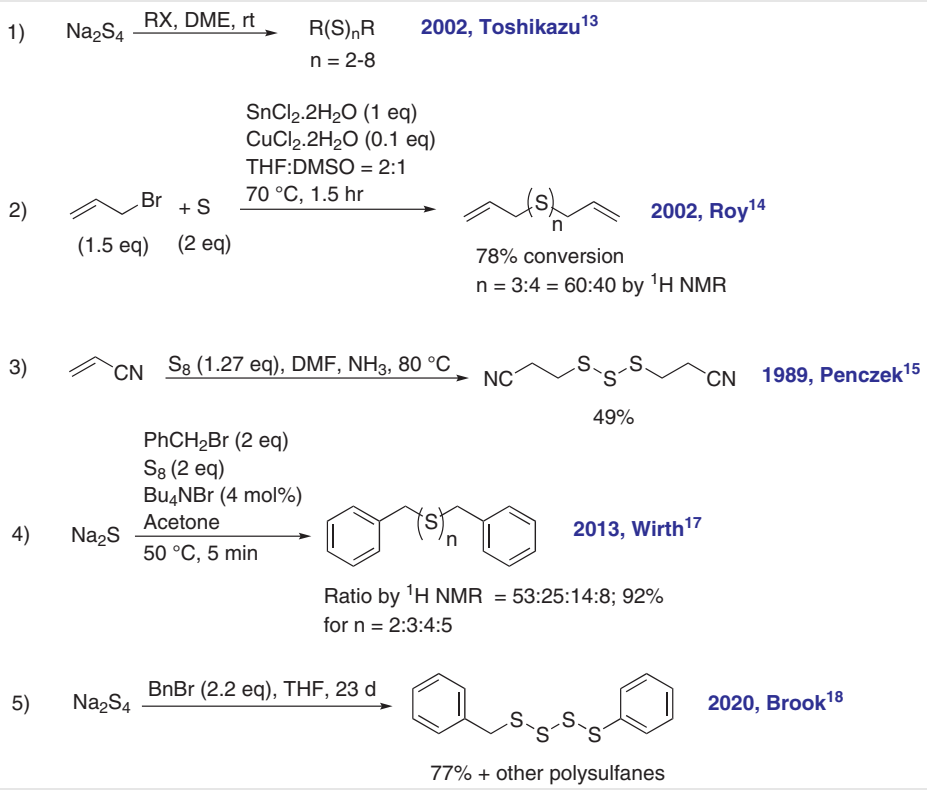

2020, Brook $^{18}$$$
77 \% \text { + other polysulfanes }
$$

Scheme 1 Some recent examples of methodology $\mathbf{A}$ for tri- and tetrasulfane synthesis

fanes can only be realistically accessed using two-bond disconnections (three synthons) in which one of the substrates accommodates two of the synthons. Several other monosulfur electrophiles have been used for both tri- and tetraorganosulfane synthesis, including thiosulfonates (Scheme 2, entry 8), ${ }^{25}$ sulfenyl halides ${ }^{26 a-e}$ (Scheme 2, entry 9), ${ }^{26 a, e}$ thiosulfonates and thiosulfinates (entry 10 for the latter, Scheme 2), ${ }^{27}$ and $\mathrm{N}$-thiophthalimides (Scheme 2, entry 11$).^{28}$ The literature also reports the extension of sulfenyl chlorides (as in entry 9 ) and bromides to reaction with $\mathrm{M}_{2} \mathrm{~S}_{2}$ for producing symmetrical tetrasulfanes in which $\mathrm{M}$ can be $\mathrm{H}^{26 \mathrm{a}-\mathrm{e}}$ and the metals ${ }^{26 \mathrm{~b}-\mathrm{d}} \mathrm{Na}, \mathrm{Ag}, \mathrm{Hg}$, $\mathrm{Tl}$ and $\mathrm{Pb}$, although the equilibrium issue mentioned earlier makes it unlikely that the tetrasulfane products generally can be isolated free of other polysulfanes as by-products. Varying the metal of the sulfide to silicon ${ }^{27,28}$ and $\operatorname{tin}^{29}$ has also been reported, as well as titanium in the form of a disulfanyl transfer agent $\left(\mathrm{Cp}_{4}^{\prime} \mathrm{Ti}_{2} \mathrm{~S}_{4}\right)^{30}$ from the extensive work by Ralf Steudel's group on titanium thiolato complexes as sulfur transfer agents. $\mathrm{Cp}_{4}^{\prime} \mathrm{Ti}_{2} \mathrm{~S}_{4}$ reacts with a sulfenyl halide (e.g., $\mathrm{CCl}_{3} \mathrm{SCl}$ ) to afford homotetrasulfanes in good yield (Scheme 2 , entry 9). ${ }^{30}$ In spite of these innovations, this methodological option B can only deliver on homosulfanes, with tetrasulfane target products often contaminated with other polysulfanes. For homotrisulfane synthesis, Field's thiosulfonate methodology (Scheme 2, entry 8$)^{25}$ is arguably the most efficient option. Scheme 2 summarises some of these examples, with a mechanism in entry 10 presented for Giuseppe Capozzi's intriguing trisulfane synthesis methodology using the reaction of bis(trimethylsilyl) sulphide with a thiosulfinate.

\subsection{Methodology C: $2 \times R S M+L g(S) L g$ $(n=1,2)$}

This is the final of the three-component methodologies and the one that is the most efficient for producing both triand tetrasulfane homo-products in relatively high yield and purity. The reagents of choice, sulfur dichloride $\left(\mathrm{SCl}_{2}\right)$ and sulfur monochloride $\left(\mathrm{S}_{2} \mathrm{Cl}_{2}\right)$, are both available in reasonable purity commercially, albeit that it is advisable to use freshly distilled material for reactions. However, despite their foul-smelling odour and tendency to disproportionate, these reagents continue to be the ones of choice up to the present time, which highlights the need for researchers to explore alternatives for bringing the field into line with modern-day, green standards.

The reaction of a thiol with $\mathrm{S}_{2} \mathrm{Cl}_{2}$ to produce a tetrasulfane, perhaps surprisingly, dates to as far back as 1923 (Scheme 3, entry 12 ) by Gopal Chandra Chakravarti. ${ }^{31}$ This was extended to include $\mathrm{SCl}_{2}$ for trisulfanes in 1947 by James Clayton. ${ }^{32}$ Later, in 1964, Takeshiga Nakabayashi demonstrated that triphenylmethanethiol (TrSH) could be used for both bis(triphenylmethyl)tri- and tetrasulfane synthesis using $\mathrm{SCl}_{2}$ and $\mathrm{S}_{2} \mathrm{Cl}_{2}$, respectively. ${ }^{33} \mathrm{Also}$, in the 1920 s, a variety of thiocarbonates were used as non-thiol, sulfur nucleophiles such as potassium thiobenzoate, ${ }^{34}$ Bender's salt $(\mathrm{EtOCO}(\mathrm{SK})=$ potassium 0 -ethylthiocarbonate $),{ }^{35}$ potassium $O$-ethyldithiocarbonate (EtOCS(SK)), and potassium ethyl trithiocarbonate (EtSCS(SK)), which gave rise to end-substituted trisulfides. ${ }^{35}$ The trend in using non-thiol nucleophiles continued with Franz Fehér's contributions in $1958^{36}$ using mercuric thiocyanate for accessing NC-(S) ${ }_{n}-\mathrm{CN}$ polysulfanes, covering both tri $\left(n=3\right.$, from $\left.\mathrm{SCl}_{2}\right)$ and tetra 
6) $\underset{\mathrm{Ph}}{\mathrm{S}^{-}} \mathrm{SO}_{3} \mathrm{Na} \stackrel{\mathrm{Na}_{2} \mathrm{~S} .9 \mathrm{H}_{2} \mathrm{O}(0.5 \mathrm{eq})}{\stackrel{\mathrm{H}_{2} \mathrm{O}, 0}{\circ}, 8 \mathrm{~h}}$

$\mathrm{Ph}_{\mathrm{P}} \widehat{\mathrm{C}}_{\mathrm{n}} \mathrm{Ph}$ 2019, Srivastava and Bhabak ${ }^{23}$

Bunte salt

1965, Milligan and Swan ${ }^{24}$

7)

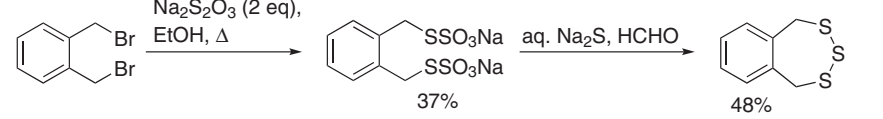

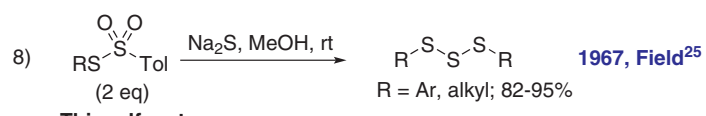

Thiosulfonate

9)

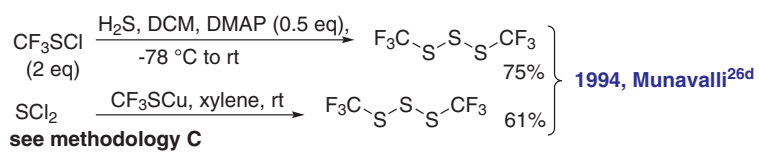

see meth

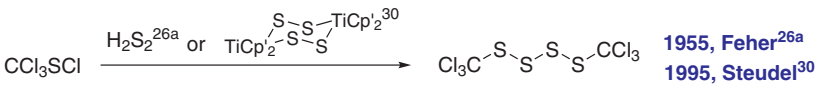

10)

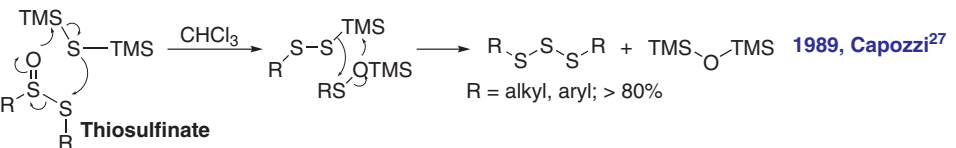

11)

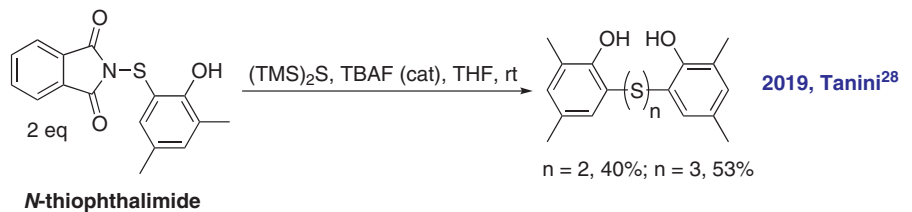

Scheme 2 Examples of methodology $\mathbf{B}$ for tri- and tetrasulfane synthesis

$\left(n=4\right.$, from $\mathrm{S}_{2} \mathrm{Cl}_{2}$ ) cases. Then, in the 1960 s and early 1970 s, the range of metal thiolates was extended to silyl ${ }^{37}$ and stannyl ${ }^{38}$ sulfides for accessing homo tri- and tetrasulfanes bearing an organic R group, respectively. In the 1990s, Ralf Steudel's group ${ }^{1,39}$ extended the metal to titanium (see methodology $\mathbf{B}^{30}$ for a variant on this theme) using an intriguing insertion reaction of titanocene dicarbonyl into a disulfide bond to form bis-thiolato complexes of titanocene of the form $(\mathrm{CO})_{2} \mathrm{Ti}(\mathrm{SR})_{2}$. The latter reacted with $\mathrm{SCl}_{2}$ or $\mathrm{S}_{2} \mathrm{Cl}_{2}$ to homologate to trisulfanes and tetrasulfane entities, respectively..$^{39}$ The method is aptly suited to the synthesis of cyclic sulfanes, although the yields are very low. Finally, Munavalli extended the synthesis of bis(trifluoromethyl)trisulfane (see entry 9 in methodology B, Scheme 2) using trifluoromethylthiocopper with $\mathrm{SCl}_{2}{ }^{26 e}$

Turning away from metal thiolates to neutral sulfur sources, in the 1980s, George Barany and Andrew Mott published extensively ${ }^{40}$ on using dimethyl dithiocarbonate and similar reagents (as neutral nucleophiles and not as salts) with both sulfur dichloride and sulfur monochloride. The prototype to afford tri- and tetrasulfanes is illustrated in Scheme 3, entry 13. Following sulfenylation of the thiocarbonate thiocarbonyl sulfur by the electrophilic chloride, dealkylation of the OMe substituent occurred to afford the final products. Once again, these products contained the end sulfur atoms functionalized as thiocarbonates, similar to work carried out in the 1920s with Bender's salt and others. ${ }^{34,35}$

Hence, by the 1990s, both sulfur dichloride and sulfur monochloride had been extensively used for both symmetrical tri- and tetrasulfane synthesis. In 1994, Professor David Harpp of McGill University in Canada, a prolific researcher in the field, published a landmark paper in Tetrahedron Letters that reported on the first use of $\mathrm{SCl}_{2}$ and $\mathrm{S}_{2} \mathrm{Cl}_{2}$ for preparing unsymmetrical tri- and tetrasulfanes. ${ }^{41}$ Although carried out in a one-pot reaction using sequential addition of the thiols, the use of freshly distilled sulfur chloride and a low reaction temperature $\left(-78^{\circ} \mathrm{C}\right)$, with pyridine as base and likely transfer agent in diethyl ether, ensured good to excellent yields of the unsymmetrical products. Until very recently, the method has stood as the method of choice for synthesizing tetrasulfanes using sulfur monochloride, although yields can be extremely low (compare with Jiang's methodology in methodology E). Recently, Harpp's method has been used to access heterotetrasulfanes showing nematocidal activity against parasitic worms (Scheme 3 , entry 14$)^{42}$ as well as cytotoxicity against HCT116 cancer cells (Scheme 3, entry 15). ${ }^{43}$ Harpp went on in 2003 to report on the use of his method for optimising 
12)

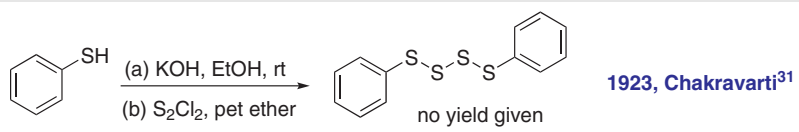

13)

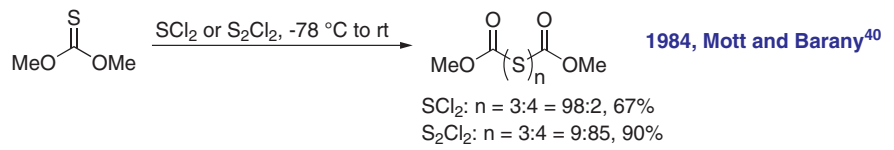

14)

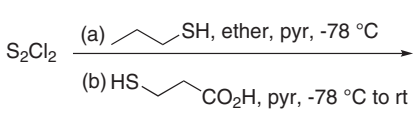

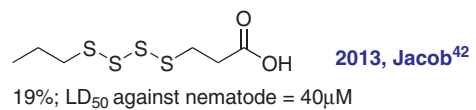

$19 \% ; \mathrm{LD}_{50}$ against nematode $=40 \mu \mathrm{M}$
15)

$17 \%$; produces $\mathrm{O}_{2}^{++}$

leading to apoptosis in HCT116 cells

Scheme 3 Reactions of sulfur chlorides to afford tri- and tetrasulfanes

the production of homotri- and tetrasulfanes with aromatic R groups. ${ }^{44}$ Scheme 3 (entries $12-15$ ) depicts reactions involving sulfur halides.

Turning to surrogates of $\mathrm{SCl}_{2}$ and $\mathrm{S}_{2} \mathrm{Cl}_{2}$ - an advisable development given their nasty nature - the first example (1960), appears to be due to an intriguing $N$-arylamidothiosulfite (formed from reaction of $N$-thionylaniline with a thiol) by Günter Kresze (Scheme 4, entry 16), ${ }^{45}$ which reacted with a thiol to produce trisulfane and disulfane mixtures. While mechanistically intriguing, inevitably a mixture of di- and trisulfanes is produced that needs to be separated. At the beginning of the 1970s, two papers emerged dealing with more reliable-looking surrogates. The first of these, by Alfred Sullivan and Kamel Boustany, ${ }^{46}$ involved synthesizing PhthNSSR from: (a) sequential substitution of $\mathrm{SCl}_{2}$ with phthalimide (to afford PhthNSCl as a surrogate of $\mathrm{SCl}_{2}$ ) and then a thiol, RSH, using triethylamine as base at low temperature, or (b) via RSSCl plus phthalimide. PhthNSSR was then shown by the authors ${ }^{46}$ to afford unsymmetrical organotrisulfanes in high yield (ca. 90\%) by reaction with a thiol in benzene at room temperature (no base needed). Further application of this reagent as a RSSLg synthon will be discussed under methodology E. The second, by David Ash and David Harpp, ${ }^{47 a}$ describes synthesis of the same disulfanyl transfer agent, PhthNSSR, but via mono-substitution of $N, N^{\prime}$-thiobisphthalimide, (PhthN $)_{2} \mathrm{~S}$, with a thiol, RSH (1 equiv), in refluxing benzene. ${ }^{47 a}$ The Harpp group went on to use this disulfanyl reagent to prepare unsymmetrical trisulfanes ${ }^{47 b, c}$ in the same way as Sullivan and Boustany. ${ }^{46}$ Of note here is that the original work on the reaction of $\mathrm{SCl}_{2}$ or $\mathrm{S}_{2} \mathrm{Cl}_{2}$ with phthalimide dates back to $\mathrm{Ku}$ verji Naik in $1921 .{ }^{48}$ However, his assignment of structure was questioned by Malda Kalnins ${ }^{49}$ in the 1960s, who established that the outcome for producing (PhthN) $)_{2} \mathrm{~S}$ versus $(\mathrm{PhthN})_{2} \mathrm{~S}_{2}$ with $\mathrm{S}_{2} \mathrm{Cl}_{2}$ is solvent dependent.
16)

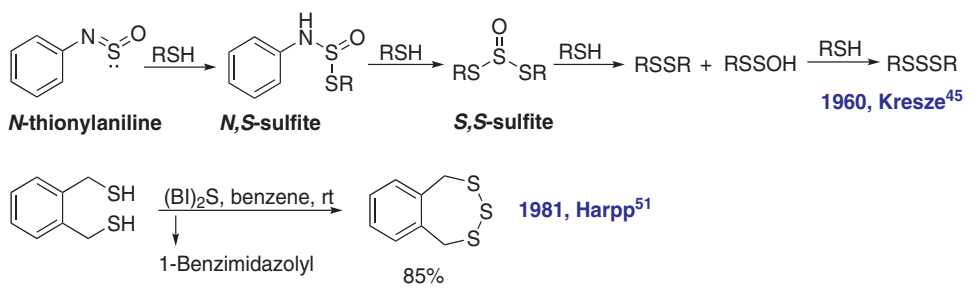

18)
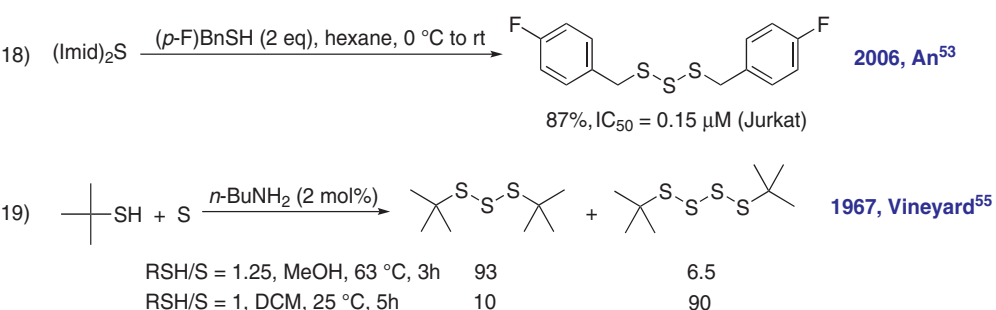

Scheme 4 Examples of methodology $\mathrm{C}$ for tri- and tetrasulfane synthesis involving sulfur halide surrogates 
These reagents, for example, (PhthN $)_{2} \mathrm{~S}$, only exchanged sluggishly with thiols, but in a seminal 1978 JACS paper, ${ }^{50}$ Harpp extended the range of options to include other $N$ based leaving groups (1,2,3-benzotriazole, benzimidazole, imidazole and 1,2,4-triazole) and demonstrated that thiols reacted smoothly (at room temperature) in the case of the benzimidazole reagent to afford the desired sulfanes (dibenzyl tri- and tetrasulfanes) in effectively quantitative yield. Cyclic trisulfanes could also be accessed in high yield using the benzimidazole reagent (Scheme 4 , entry 17). ${ }^{51} \mathrm{~A}$ few years later, Asoke Banerji ${ }^{52}$ demonstrated the use of the bis(imidazole)sulfide variant for homotrisulfane synthesis, which was used many years later by Haoyun $\mathrm{An}^{53}$ for preparing homotrisulfanes in cancer-cell cytotoxicity evaluation (Scheme 4, entry 18). ${ }^{53}$ Such transfer agents benefit from precipitation of the nitrogen ligand (imidazole in Banerji's case $)^{51}$ since the exchange can be run in hexane.

In 1984, Mott and Barany, ${ }^{54}$ extending their work on thiocarbonates as nucleophiles with sulfur halides, ${ }^{40}$ introduced a further variant on electrophilic $\mathrm{SCl}_{2}$ surrogates by introducing the reagent methoxycarbonyldisulfanyl chloride $\left(\mathrm{MeO}_{2} \mathrm{CS}_{2} \mathrm{Cl}\right)$ for trisulfane synthesis, containing $\mathrm{Cl}$ and monothiocarbonate as the two leaving groups with different leaving abilities. Strictly speaking, this sequence is a two-component category since the intermediate methoxycarbonyltrisulfane, $\mathrm{MeO}_{2} \mathrm{CSSSR}$, can be isolated (making it an RSSLg + R'SH type in a two-component sense under methodology $\mathbf{E}$ ), and will be revisited there. The same concept applies for the $\mathrm{SCl}_{2}$ surrogate, PhthSSR, which is isolable in a stable form from reaction of a thiol with PhthSCl (stable in the freezer). Finally, Xuefeng Jiang's innovative recent work on bilateral, disulfanyl scaffolds as electrophilic sulfur-transfer agents also falls under this heading. These will all be covered under methodology $\mathbf{E}$ as two-component reaction options involving RSSLg.

The final word on electrophilic surrogates in methodology $\mathbf{C}$ belongs to intriguing work by Billy Vineyard ${ }^{55}$ of the Monsanto company in the 1960s, who showed that sulfur reacted with a thiol and an amine base as catalyst to afford homotrisulfanes or tetrasulfanes in decent yields and purity depending on the nature of the thiol R group and thiol to sulfur stoichiometry. Mechanistically, Vineyard rationalised this fascinating conversion as involving attack of the thiolate (as RSM) on the $\mathrm{S}_{8}$ chain (as LgSLg) to generate a polysulfane anion that would undergo further $\mathrm{S}-\mathrm{S}$ bond substitution by a second equivalent of thiolate. Further S-S exchanges would then disproportionate to the eventual dominant product according to the $\mathrm{RSH} / \mathrm{S}$ stoichiometry. Given the nature of the starting electrophilic reactant as $\mathrm{S}_{8}$, the chemoselectivity is remarkable (Scheme 4, entry 19). Billy Vineyard later went on to be part of the Monsanto Knowles' team (with Jerry Sabacky) who were co-recipients of the 2001 Nobel Prize in Chemistry for their work on asymmetric hydrogenation (together with Ryoji Nyori). Barry Sharpless was the other recipient of the prize for his work on chirally catalysed oxidation reactions. Scheme 4 depicts relevant examples of methodology $\mathbf{C}$, involving sulfur halide surrogates.

\subsection{Methodology D: RSSM + R(S) ${ }_{n} L g, n=1,2$}

In this methodology $\mathbf{D}$, for trisulfanes, coupling occurs via a $\left[2_{\text {nuc }}+1_{\text {elec }}\right]$ mode in which the disulfanyl component is a perthiol RSSH (also known in the literature as a hydrodisulfane, hydrodisulfide, or a persulfide) or its thiolate form. Naturally, this methodology is aptly set up for the synthesis of unsymmetrical trisulfanes, which automatically covers symmetrical trisulfane synthesis too. For tetrasulfane synthesis, two manifolds can be considered as RSSM + RSSLg and RSSSM + RSLg as $\left[2_{\text {nuc }}+2_{\text {elec }}\right]$ and $\left[3_{\text {nuc }}+1_{\text {elec }}\right]$, respectively. While there does not seem to be any literature examples of the latter, the former has been demonstrated in the synthesis of $\mathrm{CF}_{3} \mathrm{SSSSCF}_{3}{ }^{56}$ for spectroscopic studies (Scheme 5, entry 20) via the reaction of $\mathrm{CF}_{3} \mathrm{SSH}$ (from the reaction of excess $\mathrm{H}_{2} \mathrm{~S}$ with $\mathrm{CF}_{3} \mathrm{SCl}$ ) 57 with $\mathrm{CF}_{3} \mathrm{SSCl}$ (most conveniently from the reaction of $\mathrm{CF}_{3} \mathrm{SH}$ with $\left.\mathrm{SCl}_{2}\right){ }^{58}$ In principle, this approach should be applicable to heterotetrasulfane synthesis, although the lengthy and old-fashioned syntheses of the reactants precludes it from modern mainstream usage.

Perthiols are well known in the biological literature in conjunction with sulfur redox biochemistry ${ }^{59}$ and were first recognized synthetically in the 1950s in seminal work by Horst Böhme. ${ }^{60}$ He demonstrated that a perthiol was reasonably stable in acidic medium (less so in a basic one) and prepared it via acid deprotection of a disulfanyl acetate, RSSAc, using ethanolic $\mathrm{HCl}$ (the RSSAc formed by coupling of acetylsulfenyl chloride with a thiol; the AcSCl formed from chlorination of acetic thioanhydride, $\mathrm{Ac}_{2} \mathrm{~S}$, with chlorine gas). Very recently, Ming Xian's group generated a perthiol from a cyclic acyl disulfide using an amine as the unmasking agent. ${ }^{61}$

In the early 1960s, a Japanese group headed by Takeshiga Nakabayashi ${ }^{62}$ extended Böhme's method to the synthesis of unsymmetrical organotrisulfanes using reaction of a perthiol with a sulfenyl chloride (Scheme 5, entry 21) or thiocyanate as electrophile. The synthesis of the two reagents had been reviewed previously by Norman Kharasch, ${ }^{63}$ and generally involved oxidising either a disulfide or a thiol with chlorine or bromine to afford the sulfenyl halide, which could be substituted with thiocyanate ion for producing the sulfenyl thiocyanate. More recently, sulfenyl chlorides, $\mathrm{RSCl}(\mathrm{R}=\mathrm{akyl}$, aryl), have been reliably prepared by reaction of a thioacetate, RSAc, with sulfuryl chloride. ${ }^{64}$ As an extension of this concept, Böhme was the first to show that a hydrodisulfide could be oxidised in virtually quantitative yield to its homotetrasulfane with iodine in methanol at room temperature (Scheme 5, entry 22). ${ }^{60}$ The reaction presumably proceeds via a RSSH + RSSLg path, 


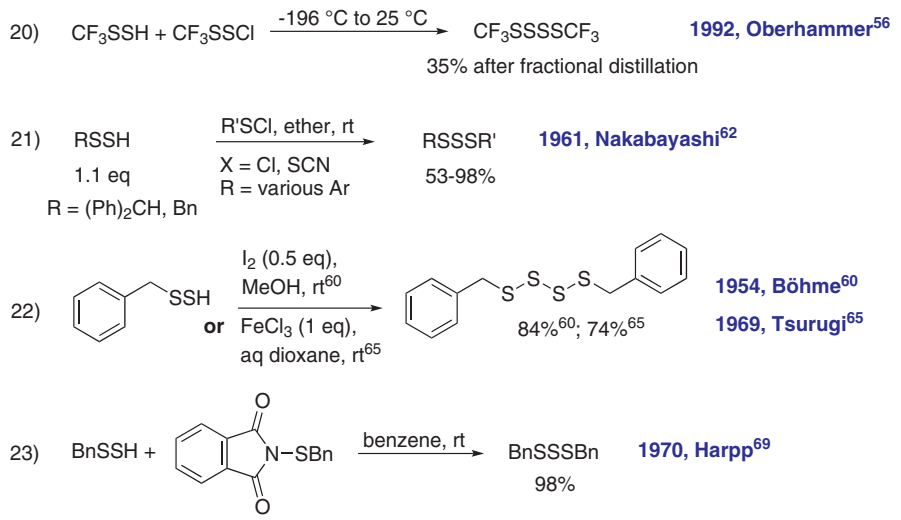

Scheme 5 Early examples of RSSH in methodology D

with $\operatorname{Lg}=\mathrm{I}$. This version by Böhme was an improvement on his formation of tetrasulfanes via the reaction of a chlorodisulfane (BzSSCl) with iodide ion, in which the intermediate iododisulfane disproportionates to the tetrasulfane $\left(\mathrm{BzS}_{4} \mathrm{Bz}\right)$ and iodine (the latter can promote by-product formation). ${ }^{77}$ Jitsuo Tsurugi later reported that the RSSH oxidative dimerization reaction could also be achieved in high yield in aqueous dioxane using ferric chloride as oxidant (Scheme 5, entry 22). ${ }^{65}$

Disulfanyl acetates have remained as popular sources for accessing perthiols to the present time, as they are readily accessible via substitution of thiotosylates (RSTs) with thioacetate ion. ${ }^{66}$ In turn, RSTs, when $\mathrm{R}=$ alkyl, can be easily synthesised via substitution of RX with thiotosylate ion, ${ }^{67}$ while for $\mathrm{R}=$ aromatic, RSTs can be accessed via reaction of a disulfide with iodine and sulfinate ion. ${ }^{68}$ Into the 1970 s, Harpp made use of this accessibility of perthiols by reacting one (BnSSH) with PhthNSBn (a Harpp transfer reagent) to form dibenzyl trisulfane (Scheme 5, entry 23) in excellent yield (98\%). ${ }^{69}$ Scheme 5 (entries 20-23) depicts these early examples of using a perthiol in the context of methodology D.

Moving on to more recent examples involving RSSH, although Harpp reported in 1976 that a sulfenylthiocarbonate $\left(\mathrm{MeO}_{2} \mathrm{CSSR}\right)$ - easily prepared via reaction of a thiol with methoxycarbonylsulfenyl chloride - deprotects to form a perthiolate anion with tert-butoxide, ${ }^{70}$ it took almost another forty years before base-mediated, disulfanyl acetate deprotection methodology appeared in the context of methodology D. Although perthiolates have the advantage of being considerably more nucleophilic than their perthiol conjugate acids, they suffer from the grave disadvantage of desulfurising to the thiolate, ${ }^{71}$ explaining why so many procedures generated using perthiols result in a mixture of di- and trisulfane. Dariusz Witt was the first to make the breakthrough in this context in $2013^{72}$ when he showed that deprotection of a disulfanyl acetate using sodium methoxide in dry methanol at $0{ }^{\circ} \mathrm{C}$ under $\mathrm{N}_{2}$ generated the corresponding perthiolate (RSS ${ }^{-}$) without loss of sulfur (by vir- tue of isolating heterotrisulfanes free of disulfane by-products). This was due to him matching the anion with an appropriate electrophile, leading to a fast coupling. The RSLg in question was in the form of a novel, cyclic sulfanyl phosphorodithioate (the two oxygens diesterified in the form of a ring), which had the added advantage that it could also be used to source the disulfanyl acetate via its reaction with KSAc. Witt prepared a library of heterotrisulfanes with different aliphatic groups (no aromatic $\mathrm{R}$ groups) in high yield and purity, although the outcome was sensitive to the choice of each of the R groups (Scheme 6, entry 24).

A few years later, in 2018, Ming Xian's group reported ${ }^{73}$ on a novel methodology for accessing the perthiol source via base deprotection of a 9-fluorenylmethyl disulfide (RSSFm), in which the focus was on R as a cysteinyl group. The deprotection to the perthiol RSSH (or perthiolate, $\mathrm{RSS}^{-}$) was achieved using DBU (2 equiv), taking advantage of the relatively acidic nature of the benzylic hydrogen of the Fm group (similar to the principle governing FMoc deprotection). The perthiolate coupled to SuccNSR, or 2-benzothiazole disulfide (Scheme 6, entry 25) in low to excellent yield (32-95\%). The targeted nature of these two recent methods ensures that homotrisulfanes do not overly interfere as by-products. Similarly, we have utilised ${ }^{74}$ Witt's conditions for disulfanyl acetate deprotection, but at $-78{ }^{\circ} \mathrm{C}$, demonstrating that a very fast reaction (within 30-60 s) occurs between a disulfanyl acetate and a thiotosylate (RSTs; $\mathrm{R}=$ alkyl or aryl) in the presence of sodium methoxide in a mixture of $\mathrm{THF} /$ methanol to afford unsymmetrical trisulfanes in high yield and purity (Scheme 6, entry 26). ${ }^{74}$

Finally, two groups have cleverly exploited certain disulfanyl reagents of the type RSSX that can generate in situ both the electrophilic (RSLg) and nucleophilic reagent (RSS-) for methodology $\mathbf{D}$. The reaction constitutes a homo-coupling with two prerequisites. Firstly, the $\mathrm{X}$ group of RSSX should be removable via an $S_{N} A c$ mechanism to liberate the perthiolate anion RSS-. Secondly, the SX group should also act as a leaving group in another molecule. Clearly, such a variant of methodology $\mathbf{D}$ is only applicable for synthesiz- 

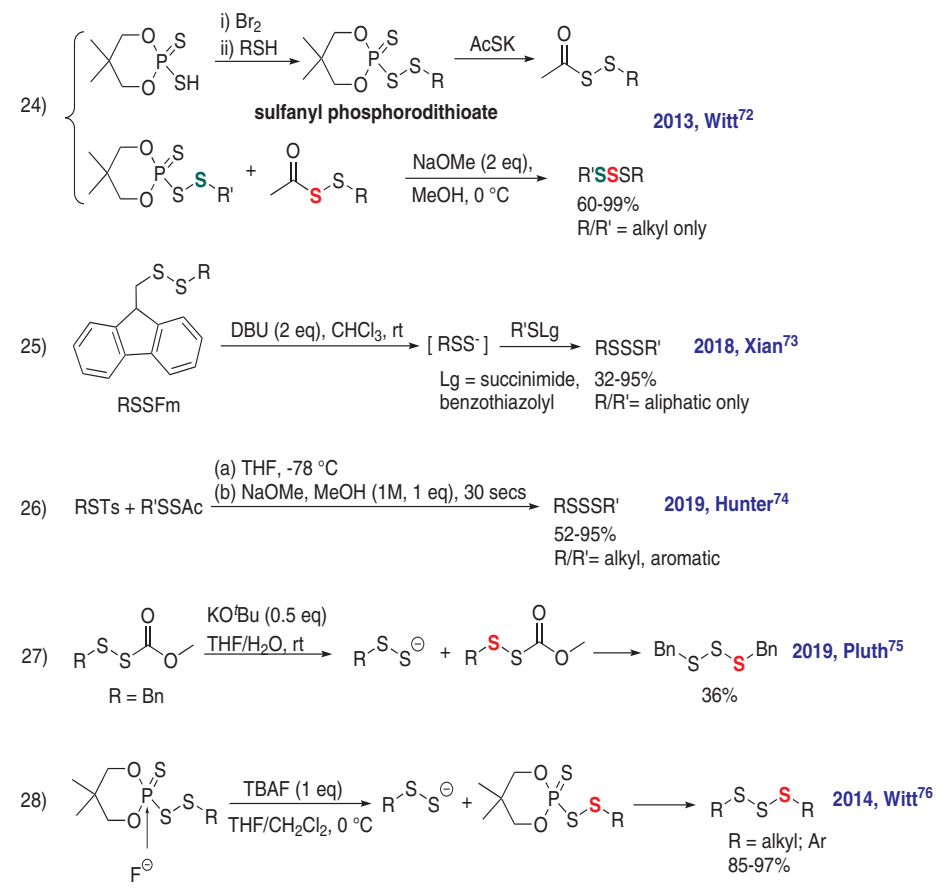

Scheme 6 Recent examples of methodology D via a perthiol, RSSH

ing homotrisulfanes, and the prototype reaction, as already mentioned, was discovered by Harpp ${ }^{70}$ in 1976. It involved reacting a sulfenyl thiocarbonate $\left(\mathrm{MeO}_{2} \mathrm{CSSR}\right)$ with methoxide in methanol as solvent at $0{ }^{\circ} \mathrm{C}$, which gave a mixture of the homodisulfane and homotrisulfane. Gratifyingly, as the steric bulk of the promotor increased, the percentage of trisulfane improved dramatically, making tert-butoxide the promoter of choice. Logically, the nucleophilic promotor stoichiometry must be less than half of the RSSX concentration. Recently, Pluth used Harpp's method to prepare dibenzyl trisulfide (BnSSSBn), which was reacted with a thiol to generate $\mathrm{H}_{2} \mathrm{~S}$ for studying as a biotransmitter. In their work, benzylsulfenyl thiocarbonate was treated with $t$-BuOK in methanol to afford an inseparable mixture of di- and trisulfanes. The chemoselectivity problem was solved by switching to a mixture of tetrahydrofuran and water, which generated hydroxide ion as promoter, resulting in the formation of product BnSSSBn cleanly, albeit in a low yield of $36 \%$ (Scheme 6, entry 27). ${ }^{75}$

The only other example of this intriguing methodology for homotrisulfane synthesis is due to Witt, ${ }^{76}$ using his sulfanyl phosphorodithioate. In his case, TBAF acted as a hard, nucleophilic promotor, reacting at the harder phosphorus centre over the softer sulfur (Scheme 6, entry 28).

In summary, although elegant in principle, the method can only be used to access homotrisulfanes. It also runs the risk of the disulfanyl anion intermediate losing sulfur to form a competing thiolate nucleophile, leading to a disulfane by-product. Scheme 6 depicts recent reactions for methodology $\mathbf{D}$ via a perthiol, RSSH.

\subsection{Methodology E: $R S M+R(S)_{n} \operatorname{Lg}(n=2,3)$}

The second (and final) of the two-component methodologies, methodology $\mathbf{E}$, is more prolific than methodology D. For trisulfane synthesis, it involves an electrophilic disulfanyl component and a nucleophilic mono-sulfur component. As with methodology $\mathbf{D}$, this methodology is also eminently suited for heterosulfane synthesis. However, unlike methodology D, E has been extended to cover tetrasulfanes via recent work by Jiang using coupling of an RSSSLg synthon with RSH. RSSLg + RSSM is also known for tetrasulfanes, but is rare, and was covered under methodology $\mathbf{D}$ for the synthesis of $\mathrm{CF}_{3} \mathrm{SSSSCF}_{3} .{ }^{56}$ To our knowledge, the variant $\mathrm{RM}+\mathrm{LgSSSSR}$ for tetrasulfanes has not been reported. For trisulfanes, the discussion using methodology $\mathbf{E}$ will centre on the scope of the RSSLg component since RSM is used as its thiol or thiolate.

In the context of trisulfanes, the earliest examples of an electrophilic disulfanyl species RSSLg in this context were with Lg as chloride, which was first studied extensively by Böhme in the $1950 s^{60,77,78}$ In addition to his work on perthiols already discussed under methodology $\mathbf{D},,^{60}$ he reacted ${ }^{77}$ chlorine with diacetyl disulfide $\left(\mathrm{Ac}_{2} \mathrm{~S}_{2}\right)$ to give a separable mixture (by vacuum distillation) of acetyldisulfanyl chloride (AcSSCl) and acetyl chloride. ${ }^{77}$ Böhme then showed that $\mathrm{AcSSCl}$ reacted with thiols to give protected unsymmetrical trisulfanes, AcSSSR. ${ }^{77}$ Hence, AcSSCl was the first synthon of this type to be accessed. While the acetyl group acted as a kind of protecting group for other conversions, for example, for perthiol production, in the present context, 
it still left the question of how to introduce the R group on the acetyl side. Hence, Böhme went on to show that sulfuryl chloride $\left(\mathrm{SO}_{2} \mathrm{Cl}_{2}\right)$ could also be used as the chlorinating agent for $\mathrm{RSSCl}$ production, here, starting with either a disulfanyl acetate RSSAc (formed from AcSCl + RSH), or a trisulfane. ${ }^{78} \mathrm{RSSCl}$ was then reacted with thiols to access unsymmetrical trisulfanes, RSSSR'. ${ }^{78}$

A few years later, in 1964 , Nakabayashi ${ }^{33}$ followed up on his synthesis of unsymmetrical trisulfanes from perthiols ${ }^{62}$ by demonstrating that $\mathrm{AcSSCl}$ (from Bohme's ${ }^{77,78}$ methods) reacted with $\mathrm{TrSH}$ (tritylthiol) to form TrSSSAc in 85\% yield, in which TrSSSAc is a precursor of TrSSSH via acid hydrolysis. ${ }^{33}$ Another method for accessing RSSCl developed around this time (1958) that is still used today is due to Fehér, ${ }^{79}$ in which the original work involved adding a thiol dissolved in carbon disulfide slowly to a large excess of sulfur dichloride (later examples used triethylamine as base) at $-78{ }^{\circ} \mathrm{C}$. The $\mathrm{RSSCl}$ was isolated by vacuum distillation. No-one can say that chemists were not brave back in the day!

Disulfanyl chlorides (or chlorodisulfanes), RSSCl, with R as alkyl or aryl groups, even more than their sulfenyl chloride counterparts, $\mathrm{RSCl}$, are highly reactive, hydrolytically sensitive compounds prone to decomposition and thus difficult to isolate in a pure form. Harpp's synthesis and application $^{80}$ of $\operatorname{Tr}(S)_{n} \mathrm{Cl}(n=1-3)$ take advantage of various as- pects of the trityl group that include imparting crystallinity and stability as well as interesting chemical properties to the $\mathrm{S}-\mathrm{Tr}$ bond. Importantly, such $\operatorname{Tr}(\mathrm{S})_{n} \mathrm{Cl}$ reagents have been used for various expressions in this $\mathbf{E}$ category. For instance, Harpp reacted $n$-BuSH with $\operatorname{Tr}(\mathrm{S})_{n} \mathrm{Cl}(n=2,3)$ to prepare the unsymmetrical tri- and tetrasulfanes, $\operatorname{TrSSSBu}^{80}$ and $\mathrm{TrSSSSBu}^{80}$ in $72 \%$ and $62 \%$ yield, respectively. Similarly, as a little-known RSSSLg + RM variant equivalent to a [0 + 3] coupling, Harpp reacted $\mathrm{TrSSSCl}$ with $n$-BuLi (THF, $-78{ }^{\circ} \mathrm{C}$ ) or $\mathrm{BuMgBr}$ (ether, $0^{\circ} \mathrm{C}$ ) to prepare the trisulfane, $\mathrm{TrSSSBu}$, in yields of around $50 \%$ after purification by chromatography. Finally, some intriguing heterolytic insertion reactions of $\operatorname{Tr}(\mathrm{S})_{n} \mathrm{Cl}$ into polysulfanes have been reported in a panoply of papers ${ }^{81}$ to complement the titanium examples ${ }^{30,39}$ cited under methodologies $\mathbf{B}$ and $\mathbf{C}$. For instance, $\operatorname{Tr}(\mathrm{S})_{n} \mathrm{Cl}(n$ $=1,2$ as the electrophilic partner) reacts with a disulfane (as the nucleophilic partner) to generate a sulfonium salt, which undergoes a secondary fragmentation/recombination with expulsion of $\mathrm{TrCl}$ to afford the tri- or tetrasulfane, depending on the specific $\operatorname{Tr}(\mathrm{S})_{n} \mathrm{Cl}$ used (Scheme 7, entry 29). ${ }^{81 c}$ Similarly, other creative expressions take advantage of the trityl group's ability to activate its adjacent $\mathrm{S}$ towards electrophilic activation, which can be used to convert a suitably engineered substrate into a cyclic tetrasulfane (Scheme 7, entry 30). ${ }^{81 e}$

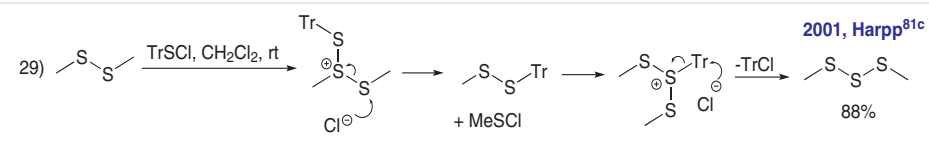

30)

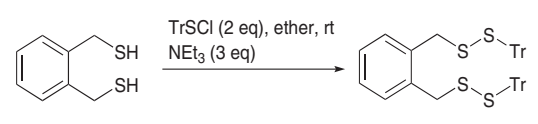

$90 \%$

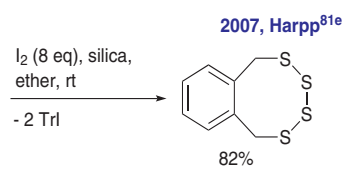

reaction of the dithiol with $\mathrm{S}_{2} \mathrm{Cl}_{2}$ gave only $18 \%$ yield
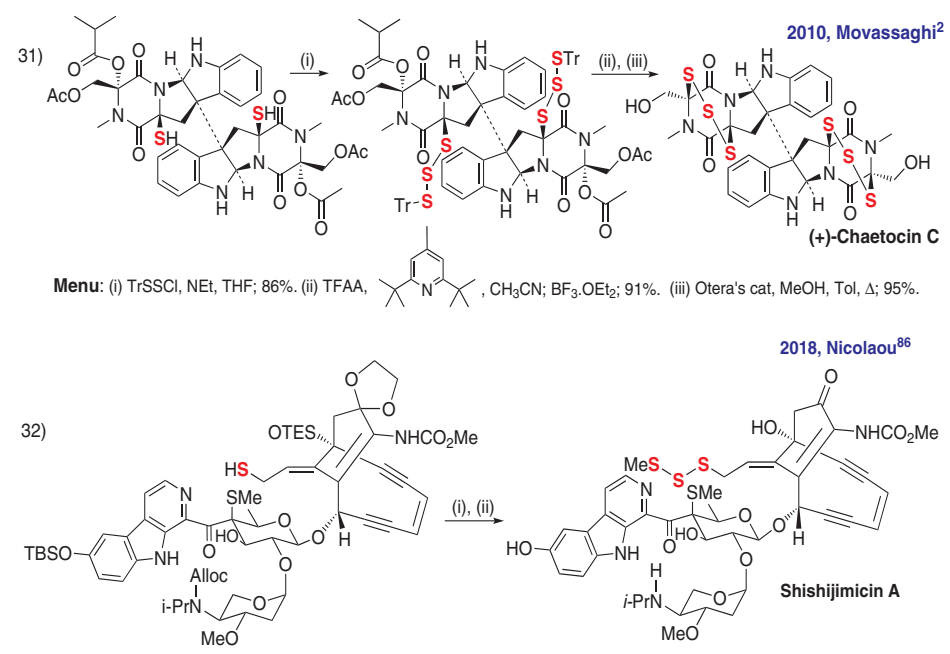

Menu: (i) PhthNSSMe (6 eq), $\mathrm{CH}_{2} \mathrm{Cl}_{2}$. (ii) Remove the protecting groups.

Scheme 7 Examples of $R(S)_{n} \mathrm{Lg}$ in insertion reactions and natural product synthesis for methodology $\mathbf{E}$ 
This chemistry has recently been put to good use in natural product total synthesis by Mohammad Movassaghi's group for constructing the trisulfane and tetrasulfane bridges of the epipolythioketopiperazine alkaloids, chaetocin $C$ and dideoxychetracin $A .^{2}$ Here, the trityl group plays an important role in bridge closure, which involves addition of the sulfur of the STr tether end onto an iminium ion to form an intermediate cyclic sulfonium ion. The trityl group provides a synchronised stabilisation of the incipient positive charge in addition to being lost as its cation to ultimately furnish the final neutral bridge moiety (Scheme 7, entry 31).

Although not necessarily used in a direct substitution, $\mathrm{RSSCl}$ synthons have inspired the development of other, more stable, derivatives of the form RSSLg, in which Lg covers phthalimide, ${ }^{46,47} S$-based leaving groups that include thiocarbonate, ${ }^{54}$ phosphorodithioate, ${ }^{82}$ and $p$-tolylsulfinate, ${ }^{83}$ as well as 0 -based in the form of alkoxy. ${ }^{84}$ Each of these important types will be discussed separately.

The first of the aforementioned variants to be discussed is the Harpp-type reagent PhthNSSR, which, for $\mathrm{R}=\mathrm{Me}$, has achieved notoriety through the enediyne antibiotics such as the calicheamicins and shishijimicins. These architecturally impressive natural products contain a methyltrithio (SSSMe) warhead trigger and are potent antitumour agents (shishijimicin A has an $\mathrm{IC}_{50}=0.48$ pM against P388 leukaemia cells and is thus ideal for incorporation as the payload into an antibody-drug conjugate (ADC)). Harpp used reaction of $\mathrm{SCl}_{2}$ with phthalimide (2 equiv) to furnish the isolable and stable mono-sulfur transfer agent, $N, N^{\prime}$-thiobisphthalimide (PhthN $)_{2} \mathrm{~S}$, which subsequently reacted with a thiol to furnish PhthNSSR ${ }^{47 a}$ as an isolable disulfanyl transfer reagent for unsymmetrical trisulfane formation. ${ }^{47 \mathrm{~b}, \mathrm{c}}$ However, in the original procedure, Harpp did not use $\mathrm{MeSH}$ as the thiol for PhthNSSMe generation. Hence, in his calicheamicinone (the aglycone of the caliceamicins) synthesis, ${ }^{85}$ Danishefsky used the Sullivan and Boustany procedure $^{46}$ using sequential double substitution of $\mathrm{SCl}_{2}$ by first, phthalimide, followed by MeSH similar to methodology $\mathbf{C}$, the reaction was carried out at $0{ }^{\circ} \mathrm{C}$ in DCM using 1 equivalent of each reactant. Unfortunately, this produced the required PhthNSSMe transfer reagent in only $19 \%$ yield. Recently, Nicolaou improved on synthesis of this reagent in his shishijimicin A synthesis ${ }^{86}$ using first reaction of sulfur monochloride $\left(\mathrm{S}_{2} \mathrm{Cl}_{2}\right)$ with phthalimide to furnish bis(1phthalimidyl)disulfane, (PhthN $)_{2} \mathrm{~S}_{2}$, which could be efficiently converted into phthalimidosulfenyl chloride, (PhthNSCl), with $\mathrm{SO}_{2} \mathrm{Cl}_{2}$ in $98 \%$ overall yield for the two steps. The sulfenyl chloride was found to be stable in a desiccator at room temperature for several months, making it a very useful reagent for hetero tri- and tetrasulfane synthesis for the future. Thereafter, inspired by previous work by Harpp, ${ }^{87}$ reaction of PhthNSCl with (TMS)SMe led to the required transfer reagent, PhthNSSMe, in essentially quantitative yield after removal of the relatively volatile TMSCl.
PhthSSMe reacted rapidly with a thiol group of the natural product at room temperature with loss of phthalimide, installing the required methyltrithio fragment (Scheme 7, entry 32). These innovations have greatly expanded the use of PhthNSSR as an important disulfanyl transfer agent. While it has been used for unsymmetrical trisulfane synthesis, ${ }^{46,47}$ the same cannot be said for tetrasulfane synthesis using a perthiol (as a RSSLg + R'SSH variant), probably because of the large number of steps needed to arrive at the two reactants. Scheme 6 depicts some of Harpp's insertion reactions $^{81}$ as well as the two natural product cases from Movassaghi $^{2}$ and Nicolaou ${ }^{86}$ cited in the text.

The second variant on RSSLg is due to Mott and Barany from 1984 in the form of the functionalised trisulfane, $\mathrm{RSSSCO}_{2} \mathrm{Me},{ }^{54}$ in which $\mathrm{Lg}$ is a thiocarbonate $\left(\mathrm{SCO}_{2} \mathrm{Me}\right)$. The $\mathrm{RSSSCO}_{2} \mathrm{Me}$ is prepared by reacting methoxycarbonyldisulfanyl chloride $\left(\mathrm{MeO}_{2} \mathrm{CSSCl}\right)$ with a thiol and can be isolated as a stable intermediate in moderate yields. This then reacts with a second thiol, using $N$-methylmorpholine (NMM) as base and promotor, with displacement of thiocarbonate, furnishing the unsymmetrical trisulfane in 50-80\% yield, albeit with contamination by the disulfide in the more reactive cases. This method has certainly stood until the present time ${ }^{88}$ as a popular way of preparing heterotrisulfanes (see Scheme 8, entry 33). However, the long synthesis of the methoxycarbonyldisulfanyl chloride ${ }^{54}$ using ungreen reagents is likely to result in the recent and improved methods for trisulfane synthesis depicted in Scheme 6 and Scheme 8 finding greater usage in the future.

The third variant of $\mathrm{Lg}$ in RSSLg to be discussed uses Dariusz Witt's cyclic phosphorodithioate, ${ }^{82}$ which was mentioned $^{72}$ in the context of methodology $\mathbf{D}$ as the RSLg partner in RSSH + R'SLg. His application of this leaving group in the RSSLg partner predates by a couple of years that of methodology D using an RSSH + RSLg approach. ${ }^{72}$ For accessing the pivotal RSSLg partner, Witt uses an intriguing synthesis in the style of methodology $\mathbf{C}$, involving a one-pot reaction of an equimolar mixture of the cyclic, diesterified phosphorodithioic acid and dodecane-1-thiol (as $\mathrm{R}^{1} \mathrm{SH}$ ) with one equivalent of sulfur dichloride at $-30{ }^{\circ} \mathrm{C}$ in DCM, using triethylamine as base. Despite the homo-coupling possibilities, the mixed substitution product as $\mathrm{R}^{1} \mathrm{SSLg}$ ( $\mathrm{Lg}=$ cyclic phosphorodithioate; $\mathrm{R}^{1}=n$-dodecyl) was isolated in $68 \%$ yield after column chromatography. Substitution of the phosphorodithioate of $\mathrm{R}^{1} \mathrm{SSL}$ with $\mathrm{R}^{2} \mathrm{SH}$ proceeded cleanly and rapidly in DCM at room temperature, again using triethylamine as base, to afford unsymmetrical trisulfanes containing a range of both aliphatic and aromatic $\mathrm{R}$ groups in $>75 \%$ isolated yield (Scheme 8 , entry 34 ). However, to avoid producing a complex mixture of symmetrical and unsymmetrical di- and trisulfane products from the final substitution, it was important to have the $\mathrm{R}^{1} \mathrm{SSLg}$ component in slight excess so as to consume the thiolate of $\mathrm{R}^{2} \mathrm{SH}$. Once again, in principle, this attractive methodology could be used for unsymmetrical tetrasulfane synthesis 
using a perthiol, $\mathrm{R}^{2} \mathrm{SSH}$, in the final substitution step, but no examples of this have appeared to date. Witt does note, however, that the scope of substitution in the $\mathrm{R}^{1}$ group of $\mathrm{R}^{1} \mathrm{SH}$ in the production of $\mathrm{R}^{1} \mathrm{SSLg}$ (and hence of $\mathrm{R}^{1}$ overall in $\mathrm{R}^{1} \mathrm{SSSR}^{2}$ ) is limited owing to the high reactivity of $\mathrm{SCl}_{2}$ in that step. For this reason, he developed the more versatile complementary methodology already described under methodology $\mathbf{D}$ based on an $\mathrm{R}^{1} \mathrm{SSH}+\mathrm{R}^{2} \mathrm{SLg}$ approach. ${ }^{72}$

The penultimate example $e^{83}$ of RSSLg to be covered is due to the group of Zhenghu $\mathrm{Xu}$, who demonstrated that $\mathrm{Lg}$ can be $p$-tolysulfonyl in $\mathrm{R}^{1}$ SSTs (Scheme 8 , entry 35 ). The one limitation is that the only $\mathrm{R}^{1}$ group covered was tertbutyl, which was probably due to it being known from previous work that sulfenyl thiotosylates (RSSTs), particularly with aromatic R groups, tend to extrude sulfur in polar solvents to afford RSTs. ${ }^{89}$ In Xu's case, the $t$-BuSSTs was readily accessed from reaction of the sulfenyl chloride, $t$-BuSCl, with TsSK. Reaction with a small library of aromatic and aliphatic thiols as $\mathrm{R}^{2} \mathrm{SH}$ with $t$-BuSSTs (1.5 equiv) in DCM at room temperature gave the desired unsymmetrical trisulfane in moderate to excellent yields (50-91\%). Not having to use a base for the final step is a clear advantage, but the method is limited by restrictions in the $\mathrm{R}^{1}$ group ( $t$-Bu only). As part of the work, Xu showed ${ }^{83}$ that $t$-BuSSTs can be cross-coupled with a boronic acid, $\mathrm{R}^{2} \mathrm{~B}(\mathrm{OH})_{2}$, using $\mathrm{CuSO}_{4} /$ $\mathrm{NaHCO}_{3}$ as promoter, to afford unsymmetrical disulfanes, $\mathrm{R}^{1} \mathrm{SSR}^{2}$.

The final word on methodology $\mathbf{E}$ is left for describing Xuefeng Jiang's recent innovative work on disulfanyl transfer agents. In this, he has significantly extended the usefulness of synthons of the type RSSLg and LgSSLg for preparing polysulfanes using a variety of stepwise substitutions by $\mathrm{S}$, $\mathrm{N}$ and, importantly, C-based nucleophiles. In the context of this section, we will focus on his approach for furnishing both unsymmetrical trisulfanes using RSSLg + RSH, and to the much-needed tetrasulfanes, using a RSSSLg + RSH approach. First, the unsymmetrical trisulfanes.

Building on earlier work that demonstrated that a disulfanyl acetate (RSSAc) could be deprotected to its perthiol in situ and oxidatively coupled with a boronic acid, $\mathrm{RB}(\mathrm{OH})_{2}$, to afford unsymmetrical disulfanes, ${ }^{66}$ in later work, ${ }^{84}$ Jiang used this protocol for converting RSSAc into the useful electrophilic synthon RSSOMe. The conditions for the crosscoupling involved using $\mathrm{Li}_{2} \mathrm{CO}_{3}$ for thioacetate deprotection in methanol, $\mathrm{PhI}(\mathrm{OPiv})_{2}$ as S-H oxidant (to S-I) and a ligated $\mathrm{Cu}$ (II) catalyst for the cross-coupling with methanol. The RSSOMe products could be purified by chromatography without decomposition or rearrangement, and then cou-

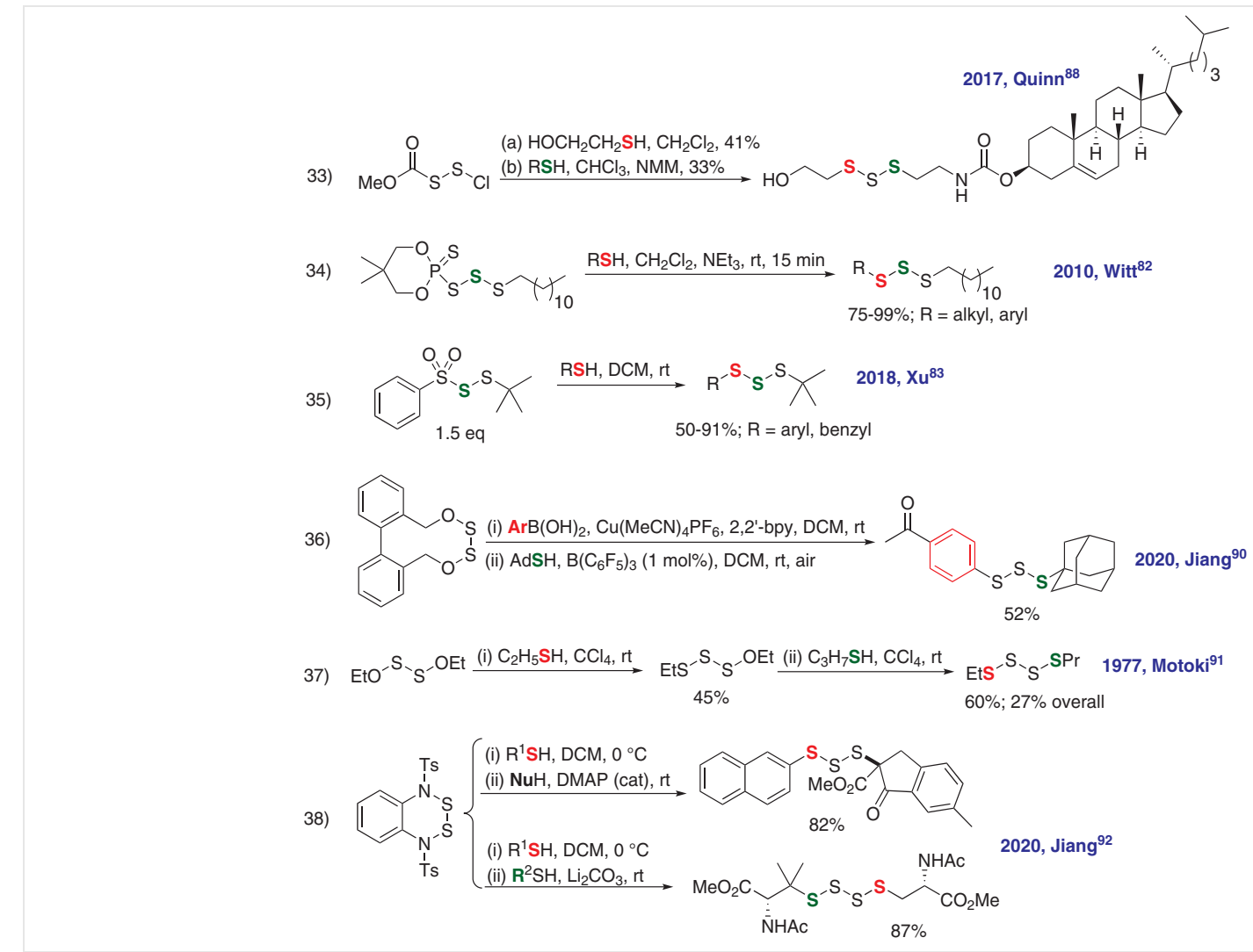

Scheme 8 Recent examples of methodology $\mathbf{E}$ 
pled with thiols in DCM at room temperature to afford a range of unsymmetrical trisulfanes $\mathrm{R}^{1} \mathrm{SSSR}^{2}$ with excellent scope for the R groups, in 40-99\% yield. However, Jiang clearly had his eye on a bilateral disulfanyl transfer reagent that would have greater versatility in producing a range of polysulfanes through the sequential substitution by $\mathrm{S}, \mathrm{N}$, or C-based nucleophiles. In 2020, he published ${ }^{90}$ his first paper (Scheme 8, entry 36) on the design and development of such a construct, building on work from Shinichi Motoki from $1977^{91}$ who had demonstrated that homodialkoxy disulfanes, ROSSOR ( $\mathrm{R}=\mathrm{Me}, \mathrm{Et})$, underwent stepwise substitution (the intermediate $\mathrm{R}^{1}$ SSSOMe could be isolated via distillation) with two different thiols to afford unsymmetrical tetrasulfanes in low yields (ca. 30\%) for the two steps (Scheme 8, entry 37). Jiang's design ${ }^{90}$ rested on incorporating the dialkoxydisulfanyl moiety into a cyclic scaffold in which the chemoselectivity of substitution could take advantage of ring-strain release in the first step, making substitution much faster for the first substitution. After considerable trial and error, he established that a ten-membered scaffold built onto a 1,1-binaphthyl template satisfied the objective. Using this template, substitution with an arylboronic acid using $\mathrm{Cu}(\mathrm{MeCN})_{4} \mathrm{PF}_{6}$ and 2,2'-bpy as ligand in DCM at room temperature smoothly generated a mono-disulfanyl ether that could be purified. However, for trisulfane production, it was more convenient to carry out the second substitution in a one-pot fashion using a thiol with $\mathrm{B}\left(\mathrm{C}_{6} \mathrm{~F}_{5}\right)_{3}$ as promoter in DCM at room temperature, generating unsymmetrical trisulfanes bearing an aryl group for $\mathrm{R}^{1}$ and either an aryl or alkyl (including hindered R groups) group for $\mathrm{R}^{2}$, in yields of $34-80 \% .{ }^{90}$ The concept could easily be extended to tetrasulfanes but changing the scaffold to an eight-membered dialkoxydisulfane built onto a phenyl ring. Substitution by $\mathrm{R}^{1} \mathrm{SH}$ proceeded at low temperature in methanol $\left(-78^{\circ} \mathrm{C}\right)$, which could be followed by $\mathrm{R}^{2} \mathrm{SH}$ with a catalytic amount (1 mol\%) of their hard oxophilic $\mathrm{B}\left(\mathrm{C}_{6} \mathrm{~F}_{5}\right)_{3}$ catalyst. The substitution chemoselectivity (mono versus di-) was ensured by virtue of a (calculated) $9.53 \mathrm{kcal} / \mathrm{mol}$ energy difference between the two S-O bond dissociation energies (Scheme 8, entry 36).

In a very recent publication, ${ }^{92}$ Jiang improved his design concept further using a six-membered scaffold fused onto an aromatic ring, incorporating a disulfonamidodisulfanyl motif (TsNSSNTs) for disulfanyl transfer. In this case, reaction conditions for each of the types (tri- and tetrasulfane) could be simplified. Hence, for the challenging tetrasulfane, selective $\mathrm{R}^{1} \mathrm{SH}$ mono-substitution could be brought about at $0{ }^{\circ} \mathrm{C}$ in DCM. Substitution with $\mathrm{R}^{2} \mathrm{SH}$ only required $\mathrm{Li}_{2} \mathrm{CO}_{3}$ as promoter in DCM at room temperature to furnish the tetrasulfane, for which 20 examples were reported, varying the $\mathrm{R}$ group significantly, in a 72-93\% yield range. In terms of yield and quality (in this case, free from other polysufanes), compared to Derbesy and Harpp's famous 1994 protocol, ${ }^{41}$ things have come some distance. Similarly, using the same six-membered, bilateral disulfenamide scaffold, unsymmetrical trisulfanes could be accessed using first substitution with $\mathrm{R}^{1} \mathrm{SH}$ at $0{ }^{\circ} \mathrm{C}$ in DCM followed by an acidic carbon nucleophile (e.g., a $\beta$-dicarbonyl type) using DMAP as promoter in DCM at room temperature. Fourteen diverse examples covering a yield range of $68-90 \%$ were reported (Scheme 8, entry 38). ${ }^{92}$ These innovations serve to demonstrate that some considerable progress has been made in unsymmetrical tri- and tetrasulfane synthesis. However, it should be noted that all of Jiang's bilateral creations stem from using $\mathrm{S}_{2} \mathrm{Cl}_{2}$ to synthesise the scaffolds. Scheme 8 depicts examples for methodology $\mathbf{E}$.

\section{Conclusions}

This review serves to present a historical and mechanistic appraisal of heterolytic methodologies available for triorgano- and tetrasulfane synthesis. The importance of such polysulfane motifs in both biology and materials science has been on the rise for some time and is likely to continue into the future. While there have been some new innovations introduced in the last ten years or so, there still pervades a dependency on using $\mathrm{SCl}_{2}$ and $\mathrm{S}_{2} \mathrm{Cl}_{2}$ as starting materials. As the demand for these polysulfane functional materials grows in the future, it is likely that researchers will have to turn their attention towards greener, catalytic methods, avoiding the production of large amounts of waste. These might mirror recent trends in disulfane synthesis via photoactive catalysts, ${ }^{93}$ aerobic oxidative coupling with metal catalysts, ${ }^{94}$ photocatalysis with quantum dots, ${ }^{95}$ electro-oxidative cross-coupling, ${ }^{96}$ and radical reactions. ${ }^{97}$ However, given the greater challenges in tri- and tetrasulfane construction compared to disulfanes, it remains to be seen how these innovative technologies might be brought to bear for tri- and tetrasulfane synthesis, particularly for unsymmetrical targets. Using sulfur as an original source, as well as carrying out assemblies in aqueous systems, are other green frontiers in this context that also need to be surmounted.

\section{Funding Information}

The authors thank the Organisation for Women in Science for the Developing World and the South African National Research Foundation for bursaries for Ms Doaa Ali and Mr Yasien Amer, respectively.

\section{References}

(1) (a) Clennan, E. L.; Stensaas, K. L. Org. Prep. Proced. Int. 1998, 30, 551. (b) Steudel, R. Chem. Rev. 2002, 102, 3905. (c) Atwood, D. A.; Zaman, M. K. Sulfur: Organic Polysulfanes, In Encyclopedia Inorg. Bioinorg. Chem; Wiley: Weinheim, 2011, DOI: 10.1002/9781119951438.eibc0215. For an updated version of 
this article, see also: (d) Steudel, R. Sulfur: Organic Polysulfanes, In Encyclopedia Inorg. Bioinorg. Chem; Wiley: Weinheim, 2011, DOI: 10.1002/9781119951438.eibc0215.pub2.

(2) Kim, J.; Movassaghi, M. J. Am. Chem. Soc. 2010, 132, 14376.

(3) (a) Cerda, M. M.; Hammers, M. D.; Earp, M. S.; Zakharov, L. N.; Pluth, M. D. Org. Lett. 2017, 19, 2314. (b) Filipovic, M. R.; Zivanovic, J.; Alvarez, B.; Banerjee, R. Chem. Rev. 2018, 118, 1253.

(4) Khongorzul, P.; Ling, C. J.; Khan, F. U.; Ihsan, A. U.; Zhang, J. Mol. Cancer Res. 2020, 18, 3.

(5) Wang, D.-Y.; Guo, W.; Fu, Y. Acc. Chem. Res. 2019, 52, 2290.

(6) (a) Mandal, B.; Basu, B. RSC Adv. 2014, 4, 13854. (b) Musiejuk, M.; Witt, D. Org. Prep. Proced. Int. 2015, 47, 95. (c) Wang, M.; Jiang, X. Top. Curr. Chem. 2018, 376, 14.

(7) (a) Strecker, W. Ber. Dtsch. Chem. Ges. 1908, 41, 1105. (b) See also: Fehér, F.; Krause, G.; Vogelbruch, K. Chem. Ber. 1957, 90, 1570.

(8) Riding, R. W.; Thomas, J. S. J. Chem. Soc., Trans. 1923, 123, 3271.

(9) (a) Filipponen, I.; Guerra, A.; Hai, A.; Lucia, L. A.; Argyropoulos, D. S. Ind. Eng. Chem. Res. 2006, 45, 7388. (b) Amrani, A.; Kamyshny, A. Jr.; Lev, O.; Aizenshtat, Z. J. Inorg. Chem. 2006, 45, 1427.

(10) (a) Fuson, R. C.; Price, C. C.; Burness, D. M.; Foster, R. E.; Hatchard, W. R.; Lipscomb, R. D. Levinstein. J. Org. Chem. 1946, 11, 487. (b) Salivon, N. F.; Filinchuk, Y. E.; Olijnyk, V. V. Z. Anorg. Allg. Chem. 2006, 62, 1610.

(11) Dannley, R. L.; Zazaris, D. A. Can. J. Chem. 1965, 43, 2610.

(12) (a) Morel, G.; Marchand, E.; Foucand, A. Synthesis 1980, 918. (b) Korchevin, N. A.; Turchaninova, L. P.; Deryagina, E. N.; Voronkov, M. G. Zh. Obshch. Khim. 1989, 59, 1785. (c) Deryagina, E. N.; Kozlov, I. A.; Vershal, V. V.; Babkin, V. A. Zh. Obshch. Khim. 1996, 66, 1279.

(13) Nobuo, Y.; Mutsuhisa, F.; Masayuki, N.; Toshikazu, T. Chem. Lett. 2002, 31, 454.

(14) Sinha, P.; Kundu, A.; Roy, S.; Prabhakar, S.; Vairamani, M. Organometallics 2001, 20, 157.

(15) Labuk, P.; Duda, A.; Penczek, S. Phosphorus, Sulfur Silicon Relat. Elem. 1989, 42, 107.

(16) Ahrika, A.; Robert, J.; Anouti, M.; Paris, J. Acta Chem. Scand. 1999, 53, 513.

(17) Baker, A.; Graz, M.; Saunders, R.; Evans, G. J. S.; Kaul, S.; Wirth, T. J. Flow Chem. 2013, 3, 118.

(18) Zheng, S.; Liao, M.; Chen, Y.; Brook, M. A. Green Chem. 2020, 22, 94.

(19) Milligan, B.; Saville, B.; Swan, J. M. J. Chem. Soc. 1961, 4850.

(20) Milligan, B.; Saville, B.; Swan, J. M. J. Chem. Soc. 1963, 3608.

(21) Bunte, H. Ber. Dtsch. Chem. Ges. 1874, 7, 646.

(22) Qiao, Z.; Jiang, X. Org. Biomol. Chem. 2017, 15, 1942.

(23) Bhattacherjee, D.; Sufian, A.; Mahato, S. K.; Begum, S.; Banerjee, K.; De, S.; Srivastava, H. K.; Bhabak, K. P. Chem. Commun. 2019, $55,13534$.

(24) Milligan, B.; Swan, J. M. J. Chem. Soc. 1965, 2901.

(25) Buckman, J. D.; Field, L. J. Org. Chem. 1967, 32, 454.

(26) (a) Fehér, F.; Berthold, H. J. Chem. Ber. 1955, 88, 1634. (b) Pitombo, L. R. M. Chem. Ber. 1962, 95, 2960. (c) Wilson, R. M.; Buchanan, D. N. In Methodicum Chimicum, Vol. 7, Chap. 33; Zimmer, H.; Niedenzu, K., Ed.; Thieme: New York, 1976. (d) Gunderman, K. D.; Hümke, K. In Methoden der Organischen Chemie, Vol. E 11 (Teilband 1); Klamann, D., Ed.; Thieme: Stuttgart, 1985, 148. (e) Munavalli, S.; Muller, A. J.; Rossman, D. I.; Rohrbaugh, D. K.; Ferguson, C. P.J. Fluorine Chem. 1994, 67, 37.

(27) Capozzi, G.; Capperucci, A.; Degl'Innocenti, A.; Del Duce, R.; Menichetti, S. Tetrahedron Lett. 1989, 30, 2991.
(28) Viglianisi, C.; Bonardi, C.; Ermini, E.; Capperucci, A.; Menichetti, S.; Tanini, D. Synthesis 2019, 51, 1819.

(29) Harpp, D. N.; Gingras, M.; Aida, T.; Chan, T. H. Synthesis 1987, 1122.

(30) Steudel, R.; Pridöhl, M.; Buschmann, J.; Luger, P. Chem. Ber. 1995, 128, 725.

(31) Chakravarti, G. C. J. Chem. Soc., Trans. 1923, 123, 964.

(32) Clayton, J. O.; Etzler, D. H. J. Am. Chem. Soc. 1947, 69, 974.

(33) Nakabayashi, T.; Tsurugi, J.; Yabuta, T. J. Org. Chem. 1964, 29, 1236.

(34) Bloch, I.; Bergmann, M. Ber. Dtsch. Chem. Ges. 1920, 53, 961.

(35) Twiss, D. J. Am. Chem. Soc. 1927, 49, 491.

(36) Fehér, F.; Weber, H. Chem. Ber. 1958, 91, 642.

(37) Abel, E. W.; Armitage, D. A. J. Chem. Soc. 1964, 5975.

(38) Wardell, J. L.; Clarke, P. L. J. Organomet. Chem. 1971, 26, 345.

(39) Steudel, R.; Kustos, M.; Münchow, V.; Westphal, U. Chem.Ber./Recl. 1997, 130, 757.

(40) Barany, G.; Mott, A. W. J. Org. Chem. 1984, 49, 1043.

(41) Harpp, D. N.; Derbesy, G. Tetrahedron Lett. 1994, 35, 5381.

(42) Czepukojc, B.; Viswanathan, U. M.; Raza, A.; Ali, S.; Burkholz, T.; Jacob, C. Phosphorus, Sulfur Silicon Relat. Elem. 2013, 188, 446.

(43) Rezkallah, D.; Schwind, L.; Abuasali, I.; Nasim, J.; Jacob, C.; Gotz, C.; Montenarh, M. Int. J. Oncol. 2015, 47, 991.

(44) Zysman-Colman, E.; Harpp, D. N. J. Org. Chem. 2003, 68, 2487.

(45) Kresze, G.; Patzschke, H. Chem. Ber. 1960, 93, 380.

(46) Sullivan, A. B.; Boustany, K. Int. J. Sulfur Chem., Part A 1971, 1, 207.

(47) (a) Harpp, D. N.; Ash, D. K. Int. J. Sulfur Chem., Part A 1971, 1, 57. (b) Harpp, D. N.; Ash, D. K. Int. J. Sulfur Chem., Part A 1971, 1, 211. (c) Harpp, D. N.; Back, T. G. Tetrahedron Lett. 1972, 1481.

(48) Naik, K. G. J. Chem. Soc., Trans. 1921, 119, 1166.

(49) Kalnins, M. V. Can. J. Chem. 1966, 44, 2111.

(50) Harpp, D. N.; Steliou, K.; Chan, T. H. J. Am. Chem. Soc. 1978, 100, 1222.

(51) Harpp, D. N.; Smith, R. A.; Steliou, K. J. Org. Chem. 1981, 46, 2072.

(52) Banerji, A.; Kalena, G. P. Tetrahedron Lett. 1980, 21, 3003.

(53) An, H.; Zhu, J.; Wang, X.; Xu, X. Bioorg. Med. Chem. Lett. 2006, 16, 4826.

(54) Mott, A. W.; Barany, G. Synthesis 1984, 657.

(55) (a) Vineyard, B. D. J. Org. Chem. 1966, 31, 601. (b) Vineyard, B. D. J. Org. Chem. 1967, 32, 3833.

(56) Gaensslen, M.; Minkwitz, R.; Molzbeck, W.; Oberhammer, H. Inorg. Chem. 1992, 31, 4147.

(57) Gombler, W.; Seel, F. Z. Naturforsch., B: Anorg. Chem., Org. Chem. 1975, 30, 169.

(58) Zack, N. R.; Shreeve, J. M. Inorg. Nucl. Chem. Lett. 1974, 10, 619.

(59) (a) Park, C.-M.; Weerasinghe, L.; Day, J. J.; Fukuto, J. M.; Xian, M. Mol. BioSyst. 2015, 11, 1775. (b) Bora, P.; Chauhan, P.; Pardeshi, K. A.; Chakrapani, H. RSC Adv. 2018, 8, 27359. (c) Benchoam, D.; Cuevasanta, E.; Möller, M. N.; Alvarez, B. Antioxidants 2019, 8, 48.

(60) Böhme, H.; Zinner, G. Justus Liebigs Ann. Chem. 1954, 585, 142.

(61) Kang, J.; Ferrell, A. J.; Chen, W.; Wang, D.; Xian, M. Org. Lett. 2018, 20, 852.

(62) Nakabayashi, T.; Tsurugi, J. J. Org. Chem. 1961, 26, 2482.

(63) Kharasch, N.; Potempa, S. J.; Wehrmeister, H. L. Chem. Rev. 1946, 39, 269.

(64) Thea, S.; Cevasco, G. Tetrahedron Lett. 1988, 29, 2865.

(65) Kawamura, S.; Abe, Y.; Tsurugi, J. J. Org. Chem. 1969, 34, 3633.

(66) Xiao, X.; Feng, M.; Jiang, X. Angew. Chem. Int. Ed. 2016, 55, 14121.

(67) Takano, S.; Hiroya, K.; Ogasawara, K. Chem. Lett. 1983, 12, 255. 
(68) Fujiki, K.; Tanifuji, N.; Sasaki, Y.; Yokoyama, T. Synthesis 2002, 343.

(69) Harpp, D. N.; Ash, D. K.; Back, T. G.; Gleason, J. G.; Orwig, B. A.; VanHorn, W. F.; Snyder, J. P. Tetrahedron Lett. 1970, 3551.

(70) Harpp, D. N.; Granata, A. Tetrahedron Lett. 1976, 3001.

(71) Bailey, T. S.; Zakharov, L. N.; Pluth, M. D. J. Am. Chem. Soc. 2014, 136,10573

(72) Lach, S.; Witt, D. Synlett 2013, 24, 1927.

(73) Xu, S.; Wang, Y.; Radford, M. N.; Ferrell, A. J.; Xian, M. Org. Lett. 2018, 20, 465.

(74) Ali, D.; Hunter, R.; Kaschula, C. H.; De Doncker, S.; Rees-Jones, S. C. M. J. Org. Chem. 2019, 84, 2862.

(75) Bolton, S. G.; Cerda, M. M.; Gilbert, A. K.; Pluth, M. D. Free Radical Biol. Med. 2019, 131, 393.

(76) Lach, S.; Witt, D. Heteroat. Chem. 2014, 25, 10.

(77) Böhme, H.; Clement, M. Justus Liebigs Ann. Chem. 1952, 576, 61.

(78) Bohme, H.; van Ham, G. Justus Liebigs Ann. Chem. 1958, 617, 62.

(79) Fehér, F.; Kruse, W. Chem. Ber. 1958, 91, 2528.

(80) Williams, C. R.; Britten, J. F.; Harpp, D. N. J. Org. Chem. 1994, 59, 806.

(81) (a) Rys, A. Z.; Harpp, D. N. Tetrahedron Lett. 2000, 41, 7169. (b) Hou, Y.; Abu-Yousef, I. A.; Harpp, D. N. Tetrahedron Lett. 2000, 41, 7809. (c) Hou, Y.; Abu-Yousef, I. A.; Doung, Y.; Harpp, D. N. Tetrahedron Lett. 2001, 42, 8607. (d) Abu-Yousef, I.; Rys, A. Z.; Harpp, D. N. J. Sulfur Chem. 2006, 27, 15. (e) Abu-Yousef, I. A.; Rys, A. Z.; Harpp, D. N. J. Sulfur Chem. 2007, 28, 251. (f) For insertion of sulfur into polysulfanes using a $\mathrm{Rh}(\mathrm{I})$ catalyst, see: Arisawa, M.; Tanaka, K.; Yamaguchi, M. Tetrahedron Lett. 2005, 46, 4797.

(82) Lach, S.; Sliwka-Kaszynska, M.; Witt, D. Synlett 2010, 2857.
(83) Wang, W.; Lin, Y.; Ma, Y.; Tung, C.-H.; Xu, Z. Org. Lett. 2018, 20 , 3829.

(84) Xiao, X.; Xue, J.; Jiang, X. Nat. Commun. 2018, 9, 2191.

(85) Haseltine, J. N.; Cabal, M. P.; Mantlo, N. B.; Iwasawa, N.; Yamashita, D. S.; Coleman, R. S.; Danishefsky, S. J.; Schulte, G. K. J. Am. Chem. Soc. 1991, 113, 3850.

(86) Nicolaou, K. C.; Li, R.; Lu, Z.; Pitsinos, E. N.; Alemany, L. B.; Aujay, M.; Lee, C.; Sandoval, J.; Gavrilyuk, J. J. Am. Chem. Soc. 2018, 140, 12120.

(87) Harpp, D. N.; Friedlander, B. T.; Larsen, C.; Steliou, K.; Stockton, A. J. Org. Chem. 1978, 43, 3481.

(88) Ercole, F.; Whittaker, M. R.; Halls, M. L.; Boyd, B. J.; Davis, T. P.; Quinn, J. F. Chem. Commun. 2017, 53, 8030.

(89) (a) Harpp, D. N.; Ash, D. K.; Smith, R. A. J. Org. Chem. 1979, 44, 4135. (b) Williams, C. R.; Macdonald, J. G.; Harpp, D. N.; Steudel, R.; Foerster, S. Sulfur Lett. 1992, 13, 247.

(90) Xue, J.; Jiang, X. Nat. Commun. 2020, 11, 4170.

(91) Kagami, H.; Motoki, S. J. Org. Chem. 1977, 42, 4139.

(92) Xue, J.; Jiang, X. Org. Lett. 2020, 22, 8044.

(93) Oka, M.; Katsube, D.; Tsuji, T.; Iida, H. Org. Lett. 2020, 22, 9244.

(94) (a) Qiu, X.; Yang, X.; Zhang, Y.; Song, S.; Jiao, N. Org. Chem. Front. 2019, 6, 2220. (b) Song, L.; Li, W.; Duan, W.; An, J.; Tang, S.; Li, L.; Yang, G. Green Chem. 2019, 21, 1432.

(95) Li, X.-B.; Li, Z.-J.; Gao, Y.-J.; Meng, Q.-Y.; Yu, S.; Weiss, R. G.; Tung, C.-H.; Wu, L.-Z. Angew. Chem. Int. Ed. 2014, 53, 2085; Angew. Chem. 2014, 126, 2117.

(96) Huang, P.; Wang, P.; Tang, S.; Fu, Z.; Lei, A. Angew. Chem. Int. Ed. 2018, 57, 8115; Angew. Chem. 2018, 130, 8247.

(97) Wu, Z.; Pratt, D. A. J. Am. Chem. Soc. 2020, 142, 10284. 